\title{
Implementation of Rock Typing on Waterflooding Process During Secondary Recovery in Oil Reservoirs: A Case Study, El Morgan Oil Field, Gulf of Suez, Egypt
}

\author{
Ahmed E. Radwan $\oplus^{1,2,4}{ }^{1,}$ Bassem S. Nabawy, ${ }^{3}$ Ahmed A. Kassem, ${ }^{2}$ and Walid S. Hussein ${ }^{2}$
}

Received 15 July 2020; accepted 24 December 2020

Published online: 11 January 2021

Waterflooding is one of the most common secondary recovery methods in the oil and gas industry. Globally, this process sometimes suffers a technical failure and inefficiency. Therefore, a better understanding of geology, reservoir characteristics, rock typing and discrimination, hydraulic flow units, and production data is essential to analyze reasons and mechanisms of water injection failure in the injection wells. Water injection failure was reported in the Middle Miocene Hammam Faraun reservoir at El Morgan oil field in the Gulf of Suez, where two wells have been selected as injector's wells. In the first well (A1), the efficiency of injection was not good, whereas in the other analog A2 well good efficiency was assigned. Therefore, it is required to assess the injection loss in the low efficiency well, where all aspects of the geological, reservoir and production data of the studied wells were integrated to get a complete vision for the reasons of injection failure. The available data include core analysis data (vertical and horizontal permeabilities, helium porosity, bulk density, and water and oil saturations), petrographical studies injection and reservoir water chemistry, reservoir geology, production, and injection history. The quality of the data was examined and a set of reliable $X-Y$ plots between the available data were introduced and the reservoir quality in both wells was estimated using reservoir quality index, normalized porosity index, and flow zone indicator. Integration and processing of the core and reservoir engineering data indicate that heterogeneity of the studied sequence was the main reason for the waterflooding inefficiency at the El Morgan A1 well. The best reservoir quality was assigned to the topmost part of the reservoir, which caused disturbance of the flow regime of reservoir fluids. Therefore, it is clearly indicated that rock typing and inadequate injection perforation strategy that has not been aligned with accurate hydraulic flow units are the key control parameters in the waterflooding efficiency.

KEY WORDS: Waterflooding, Flow zone indicator, Rock quality index, Water injection, Rock typing.

${ }^{1}$ Faculty of Geography and Geology, Institute of Geological Sciences, Jagiellonian University, Gronostajowa 3a, 30-387 Kraków, Poland.

${ }^{2}$ Exploration Department, Gulf of Suez Petroleum Company (GUPCO), Cairo, Egypt.

${ }^{3}$ Department of Geophysical Sciences, National Research Center, Cairo, Egypt.

${ }^{4}$ To whom correspondence should be addressed; e-mail: radwanae@yahoo.com

\section{INTRODUCTION}

Secondary oil recovery is employed to enhance oil production when reservoir pressure depletion starts and primary recovery production declines significantly. Gas injection and waterflooding are the most common methods for secondary recovery. Injection increases the formation pressure by 
injecting fluids into the depleted reservoir. A pressure-maintenance program can begin during the primary recovery stage, but it is a form of enhanced recovery. Gas is injected into the primary or secondary gas caps, while water is injected into the production zone to push oil out of the reservoir. Injected gas either expands, increasing the reservoir pressure, or dissolves as solution gas in the oil at pressures lower than the bubble pressure point which decreases viscosity and increases the flow rate. However, the high cost of surface facilities and gas injection stations are disadvantages of gas injection, in addition to the compressibility of gas that reduces the volume of the injected gas volume at depth, i.e., decreasing the potential oil recovery.

Waterflooding, on the other hand, has been used to provide pressure support and increase the well productivity, for more than 50 years (Craig 1971; Willhite 1986; Tang and Morrow 1997; Gulick and McCain 1998; Feng et al. 2009; Morrow and Buckley 2011; Kok 2011; Nasralla et al. 2011; Shiran and Skauge 2013; Al-Attar et al. 2013; Yasari et al. 2013; Kalam 2016; Colombo and McNeice 2017; Radwan 2018; Wood and Yuan 2018; Ahmed 2019; Radwan et al. 2019a, c, d; Kalam et al. 2020). Waterflooding also serves to improve sweep efficiency, increasing reservoir pressure when the reservoir's natural energy is not sufficient to push the oil towards the producing well. During waterflooding, the oil recovery increases by pressure maintenance, where water displaces oil in the pore space. The efficiency of such displacement depends on factors such as reservoir rock characteristics and oil viscosity. The advantages of waterflooding include: it is not expensive, highly effective, and water for injection is generally available. The availability of gas or water is the main factor in choosing the injector fluid, which is based on the reservoir-drive mechanism, either water drive or gas cap drive. Therefore, employing waterflooding as the secondary recovery procedure has priority in Egyptian oil fields controlled by the water drive mechanism.

Delineating the reservoir rock properties is necessary to plan water floods including reservoir depositional environment, diagenetic history, structures, interconnectedness of pore spaces, and water/ oil to rock characteristics. Routine core analysis is the most precise tool to understand reservoir characteristics (Ebanks et al. 1987; Scheihing et al. 2002; El Sharawy and Nabawy 2016a, b; Nabawy and Barakat 2017; Radwan et al. 2019a). Incompatibility between reservoir properties, fluids and injected water properties, and the presence of fine solids in water for injection may contribute to formation damage in some reservoirs (Bennion et al. 1996, 1998; Moghadasi et al. 2002; Yuan and Wood 2018). Reservoir geology, thus, is a key factor to achieve waterflooding project efficiency, where it leads to bridging the gap between water floods and the influence of reservoir properties.

The present study aims to analyze the water injection failure in a given well (A1 well) at El Morgan oil field in the Gulf of Suez in Egypt by understanding the reservoir rock properties in the A1 well and by comparison with an analog well, the A2 well, where the analog A2 well showed high water flood efficiency than the A1 well. This study is an attempt to understand the reasons for this failure, to study the mechanism of water flow inside the reservoir during flooding, to highlight impacts of reservoir geology and properties on injection loss, and to propose effective solutions to overcome the formation damage in the A1 well.

\section{LITHOSTRATIGRAPHY AND GEOLOGIC SETTING}

The Gulf of Suez is a rift basin of the OligoceneMiocene age. It is considered the main oil-producing province in Egypt, and El Morgan Field is one of the most important oil fields in the Gulf of Suez (Bentley and Biller 1990; Hughes et al. 1997; Salah and Alsharhan 1997; El Sharawy and Nabawy 2018, 2019; Radwan 2018; Radwan et al. 2019a). El Morgan oil field is separated, by the EL Morgan hinge zone, into the north and south El Morgan fields. Its northern part is in the central part of the Gulf of Suez basin, while its southern part is in the southern Gulf of Suez (Fig. 1a, b). The studied well (A1 well) and, its analog well (A2 well), are located in the southern part of El Morgan field as shown in Figure 1b.

The stratigraphic units in the Gulf of Suez can be subdivided into three mega sediment groups (Fig. 2): (1) the Cambrian-Oligocene pre-rift sequence; (2) the Oligocene-Miocene syn-rift sequence (the core of the present study), which comprises the main hydrocarbon reservoirs as well as seals in the Gulf of Suez (Nukhul, Rudies, Kareem, Belayim, South Gharib, Zeit, and post-Zeit seals and reservoir rocks); and (3) the post-rift postMiocene mega-sequence (Bosworth and McClay 2001; Attia et al. 2015; Nabawy and El Sharawy 2015; Abudeif et al. 2016a, 2016b, 2018; Radwan 


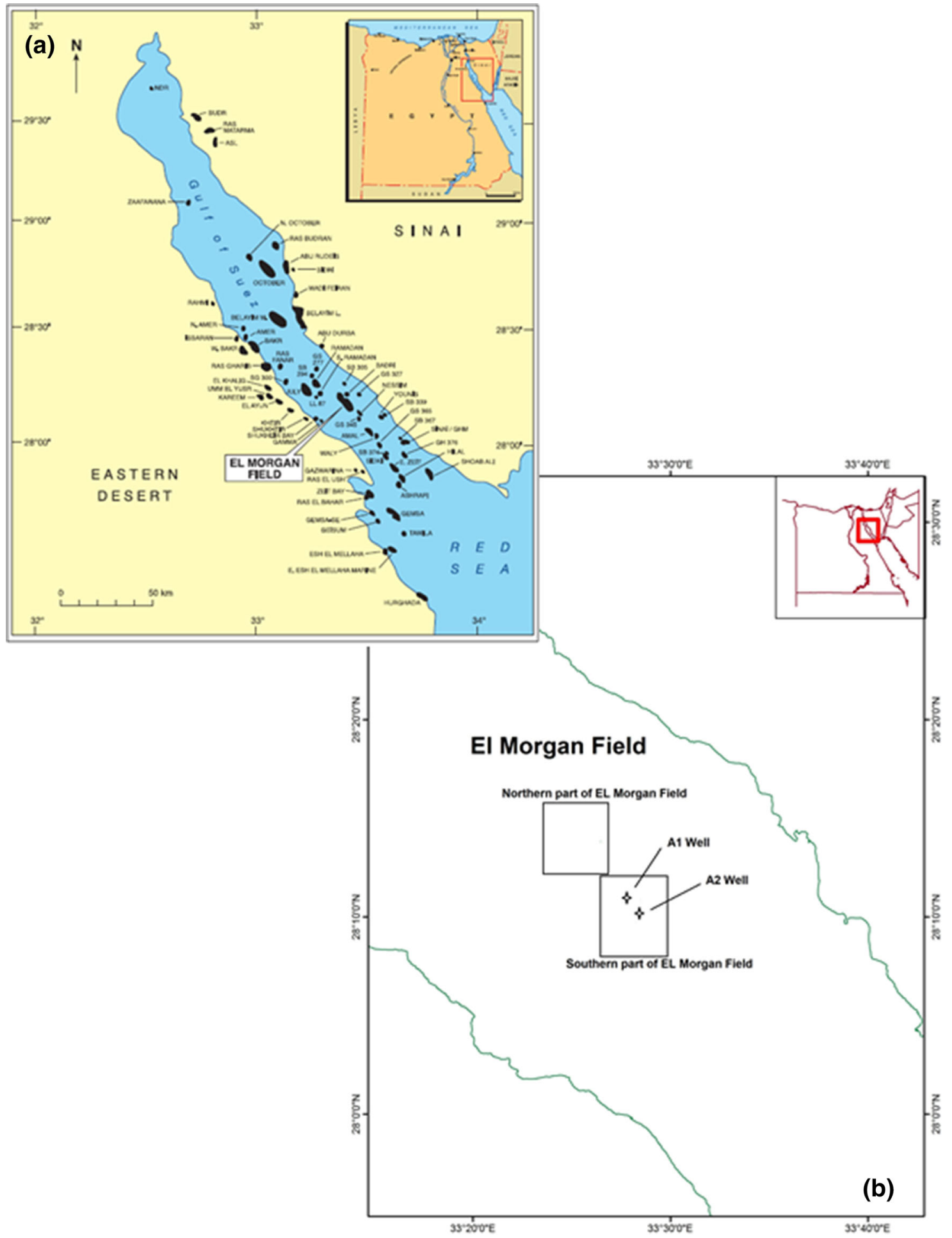

Figure 1. The main hydrocarbon oil fields in the Gulf of Suez showing the location of El Morgan oil Field in the southern province of the Gulf of Suez, Egypt (EGPC 1996). 


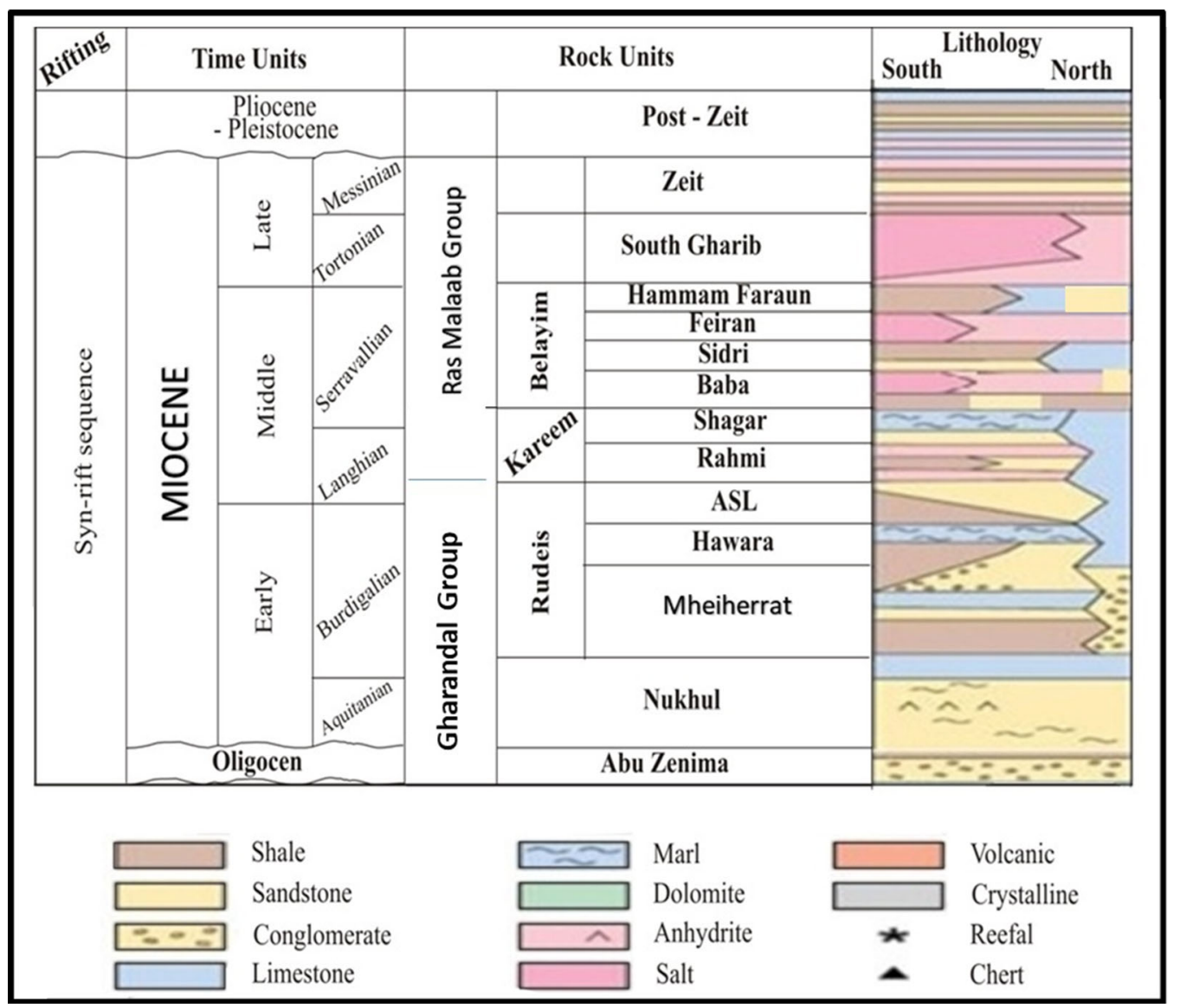

Figure 2. Syn-rift stratigraphic column of El Morgan oil field shows the geologic setting of the studied wells (Hermina et al. 1989; Attia et al. 2015; Abudeif et al. 2016a, b, 2018).

et al. 2019b, 2020a, b, c, d; Kassem et al. 2021). Hermina et al. (1989) subdivided the Miocene synrift sequences in the Gulf of Suez into two main groups: (1) Early to Middle Miocene Gharandal Group (Early Miocene Nukhul Formation, Rudies Formation, and Middle Miocene Kareem Formation); and (2) Middle to Late Miocene Ras Malaab Group (Middle to upper Serravallian Belayim Formation, and Late Miocene South Gharib and Zeit Formations (El-Gezeery and Marzouk 1974; Abdelghany et al. 2020; Radwan 2020a, b, c; Radwan et al. 2020a, b).

The Middle to Upper Serravallian Belayim Formation, which is the most important syn-rift oil reservoirs, is unconformably underlain by the Kareem Formation and its contact with the overlying South Gharib Formation is a disconformity. The Belayim Formation shows very good hydrocarbon accumulations within its sandstone interbeds (Richardson and Arthur 1988; EGPC 1996; Al- sharhan 2003; Attia et al. 2015; Nabawy and Barakat 2017; Radwan and Sen 2020). The Belayim Formation is composed of four members, the Hammam Faraun (top of Belayim Formation), Feiran, Sidri, and Baba (base of Belayim Formation). The Baba and Feiran members are evaporites (salt and anhydrite), while the Hammam Faraun and Sidri members are sandstones and shales intercalated with evaporites and carbonates. The Hammam Faraun member is a stacked alluvial fan delta system deposited in a shallow marine environment. It is composed of shale interbedded with sandstone beds and thin carbonate beds (Khalil and Meshrif 1988; Rashed 1990; EGPC 1996; Hughes et al. 1997; Gawad et al. 1986; Alsharhan 2003; Jackson et al. 2006; Radwan 2014; Nabawy and El Sharawy 2015; Ali et al. 2016; Nabawy and Barakat 2017; Abudeif et al. 2018; Radwan et al. 2019a; Radwan 2020d). The general Lithostratigraphic column of El Morgan oil field is shown in Figure 2. 


\section{DATA AND METHODOLOGY}

The present study integrated available geological, reservoir, and production data from the Hammam Faraun reservoir $(91.44 \mathrm{~m})$. A quality control examination on these data was applied to understand the low injection efficiency and to outline the main reasons for this problem. The available data include core analyses, X-ray diffraction (XRD), mineral composition, chemical composition of the injected water, reservoir fluids, reservoir geology, completion fluids, and offset well production data, as well as history of oil production, stimulation, and workover operations. In addition, the composite mud log, geological reports, and the electrical logs were also used to assess the Hammam Faraun clastics in the studied wells.

Analysis of the Hammam Faraun reservoir began with the selection of the analog well, core description, mineralogical analysis, reservoir discrimination into rock types, and reservoir quality assessment for each lithology.

\section{Selection of Analog Well}

Two wells have been used in the current study. The first is A1 well, which is the case of unsuccessful water injection well. The second is A2 well, which is a successful water injection analog well. The selection of A2 well as analog well has been built according to its successful injection scheme, and its similar characteristics with the unsuccessful A1 well in terms of geology, reservoir, and well design. In terms of geology, the two wells have relatively similarity in lithology, formation thickness, porosity, permeability, water saturation, log response, and structural position (Fig. 1). In terms of the reservoir, the two wells have relatively the same fluids, pore pressure and temperature; hence, they have been drilled in the same reservoir (Table 1). In addition, the two wells have the same well design including casing design, completion design, technology, completion fluids and injected fluids. Thus, it was concluded that the A2 well is an excellent candidate for being analog well for the unsuccessful A1 well.

\section{Core Data Analysis}

In total, 176 samples from the Hammam Faraun were studied in A1 well and 165 samples from the analog A2 well. The selected samples were described and analyzed at GUPCO laboratories in Cairo and Ras Shukeir city. Core analysis included average grain size, bulk and grain density $\left(\sigma_{\mathrm{b}}, \sigma_{\mathrm{g}}\right)$, helium porosity $\left(\varnothing_{\mathrm{He}}\right)$, horizontal and vertical permeability $\left(k_{\mathrm{H}}, k_{\mathrm{V}}\right)$, permeability anisotropy $\left(\lambda_{k}\right)$, oil and water saturation $\left(S_{\mathrm{o}}, S_{\mathrm{w}}\right)$, reservoir quality index (RQI), and flow zone indicator (FZI).

\section{Mineral Composition Analysis}

Twenty-three polished thin sections were studied. These represent different lithologies in the two wells. Petrographic analysis of the thin sections was used to describe mineral composition, pore types, and cement to better understand rock types and reservoir discrimination. In addition, XRD analysis was performed to describe the main mineral constituents and authigenic clay minerals of the studied samples.

\section{Reservoir Characterization}

The RQI, normalized porosity index (NPI), and FZI were applied to evaluate reservoir quality and characterize the main reservoir properties (Amaefule et al. 1993). The concept of hydraulic flow units (HFUs) was used to examine the efficiency of fluid flow and storage capacity within Hammam Faraun reservoir. RQI, NPI and FZI values were calculated based on measured core porosity $\left(\varnothing_{\mathrm{He}}\right)$ and permeability $(k)$ values following the standard reservoir quality techniques (Table 2, Nabawy and Al-Azazi 2015)

$$
\begin{gathered}
\mathrm{RQI}=0.0314\left(k / \varnothing_{\mathrm{He}}\right)^{0.5} \\
\mathrm{NPI}=\varnothing_{\mathrm{He}} /\left(1-\varnothing_{\mathrm{He}}\right) \\
\mathrm{FZI}=\mathrm{RQI} / \mathrm{NPI}
\end{gathered}
$$

where $k$ is in md and $\varnothing_{\mathrm{He}}$ in decimal. Reservoir parameters were then ranked following the ranking of Nabawy and Al-Azazi (2015) and the final reservoir rank, represented by the reservoir potentiality index (RPI), was then calculated as:

$$
\mathrm{RPI}=\left(\mathrm{RQI}_{\mathrm{rank}}+\mathrm{FZI}_{\mathrm{rank}}\right) / 2 .
$$

To examine reservoir anisotropy, permeability anisotropy $\left(\lambda_{k}\right)$ was calculated as (Serra 1984): 
Table 1. The Reservoir Engineering Parameters of Hammam Faraun Reservoir in the Two Studied Wells at the Time of Conversion to Injection Wells

\begin{tabular}{lll}
\hline Parameters & A1 well & A2 well \\
\hline Initial formation pressure & $4900 \mathrm{psi}$ & $4900 \mathrm{psi}$ \\
Present formation pressure & $2400 \mathrm{psi}$ & $2410 \mathrm{psi}$ \\
Pressure gradient through the water zone & $0.454 \mathrm{psi} / \mathrm{ft}$ & $0.454 \mathrm{psi} / \mathrm{ft}$ \\
Reservoir temperature & $154^{\circ} \mathrm{F}$ & $153^{\circ} \mathrm{F}$ \\
Average porosity & $23 \%$ & $22 \%$ \\
Average Permeability & $100 \mathrm{md}$ & $105 \mathrm{md}$ \\
Total drilled depth & $8450 \mathrm{ft}$ & $8600 \mathrm{ft}$ \\
Total Perforated thickness & $220 \mathrm{ft}$ & $190 \mathrm{ft}$ \\
Average API gravity & $27^{\circ} \mathrm{API}$ & $27^{\circ}$ API \\
\hline
\end{tabular}

$1 \mathrm{ft}=0.3048 \mathrm{~m} .1 \mathrm{psi}=6894.76 \mathrm{~Pa} .32^{\circ} \mathrm{F}=\left(0^{\circ} \mathrm{C} \times 9 / 5\right)+32$

Table 2. Ranking the Reservoir Rocks Based on Porosity $(\varnothing)$, Permeability $(k)$, Reservoir Quality Index (RQI), Flow Zone Indicator (FZI), and Reservoir Potentiality Index (RPI) (Nabawy and Barakat 2017; Nabawy et al. 2018b)

\begin{tabular}{|c|c|c|c|c|c|c|c|c|c|}
\hline Porosity (\%) & Rank & Permeability (md) & Rank & RQI $(\mu \mathrm{m})$ & Rank & $\mathrm{FZI}(\mu \mathrm{m})$ & Rank & $\begin{array}{l}\text { RPI } \\
0.00\end{array}$ & Rank \\
\hline $25<\varnothing$ & 1 & $1000<k$ & 1 & $5.0<\mathrm{RQI}$ & 1 & $15.0<\mathrm{FZI}$ & 1 & Excellent & 1 \\
\hline $20<\varnothing \leq 25$ & 2 & $100<k \leq 1000$ & 2 & $2.0<\mathrm{RQI} \leq 5.0$ & 2 & $10.0<\mathrm{FZI} \leq 15.0$ & 2 & Very good & 2 \\
\hline $15<\varnothing \leq 20$ & 3 & $10<k \leq 100$ & 3 & $1.0<\mathrm{RQI} \leq 2.0$ & 3 & $5.0<\mathrm{FZI} \leq 10.0$ & 3 & Good & 3 \\
\hline $10<\varnothing \leq 15$ & 4 & $1.0<k \leq 10$ & 4 & $0.50<\mathrm{RQI} \leq 1.0$ & 4 & $2.5<\mathrm{FZI} \leq 5.0$ & 4 & Fair & 4 \\
\hline $5<\varnothing \leq 10$ & 5 & $0.1<k \leq 1.0$ & 5 & $0.25<\mathrm{RQI} \leq 0.50$ & 5 & $1.0<\mathrm{FZI} \leq 2.5$ & 5 & Poor & 5 \\
\hline$\varnothing \leq 5$ & 6 & $k \leq 0.1$ & 6 & $\mathrm{RQI} \leq 0.25$ & 6 & $\mathrm{FZI} \leq 1.0$ & 6 & Impervious & 6 \\
\hline
\end{tabular}

$$
\lambda_{k}=\left(k_{\mathrm{H}} / k_{\mathrm{V}}\right)^{0.5}
$$

where $k_{\mathrm{H}}$ is horizontal permeability and $k_{\mathrm{V}}$ is vertical permeability. Eventually, reservoir zonation was applied and matched vertically with the petrophysical and reservoir quality parameters of the cored intervals.

\section{Reservoir Engineering Data}

Reservoir engineering data included reservoir production parameters, production history, injection history, fluids parameters, and fluid chemistry analysis. These data were analyzed and processed to determine a reliable characterization for the inefficient waterflooding problem in the $\mathrm{A} 1$ well by examining the efficiency of water injection in each perforated section. The measurements of injection per each zone have been determined according to the production logging spinner surveys (PLSS) and production logging tools (PLT).

\section{RESULTS AND DISCUSSION}

\section{Mineral Composition and Rock Typing}

Mineral composition of reservoir sequence has priority when evaluating waterflooding injection efficiency, where some flow units are more efficient than others. The presence of permeable or impermeable layers, different rock quality, lateral extension of porous and permeable layers, directional permeability and fractures, all contribute to the heterogeneity and homogeneity throughout the reservoir. Core description, petrographical studies, and XRD analysis were integrated for rock typing, as discussed below.

\section{A1 Well}

In A1 well four microfacies can be identified on the basis of their mineral composition and pore types: (1) calcareous arkose; (2) sandy dolomitic limestone; (3) argillaceous arkose; and (4) calcareous to ferruginous arkose. 
Sandy Dolomitic Limestone Microfacies The sandy dolomitic limestone consisted of light grey, very hard, dense, compact and microcrystalline limestone streaks, and dolomitic limestone and dolostone streaks. The calcareous streaks were usually near the top and bottom parts of the sequence. Burrowing and boring are evident in some parts. It can be described as micrite with some pseudo-sparite streaks, and some ill-sorted fine to coarse-grained quartz and feldspar grains. This microfacies was highly fossiliferous containing mollusks, echinoderms, and coral. The micritic groundmass was generally dolomitic and can be considered dolostone with some argillaceous patches. Porosity was poor to good (5-15\%) with several types of porosity: (a) micro-inter-crystalline pore spaces; (b) micro- to meso-pore vuggy spaces; (c) micro- to meso- inter- and intra-particle pores within the Mollusca and coral remains; and (d) meso-channel pore spaces.

Calcareous to Ferruginous Arkose Microfacies These ferruginous arkose streaks were scattered through the productive zone. The arkose was poorly sorted, medium- to coarse-grained, fining-upward, ferruginous sandstone. The clasts were polycrystalline, medium to coarse-grained, quartz grains with abundant feldspars, occasional lithic fragments, with dolomitic and ferruginous micro-sparite cement (Fig. 3a). Some clay and evaporite patches and very fine pyrite grains were present. The quartz and feldspar grain contacts were point, suture, and straight (Fig. 3a). The porosity of this ferruginous microfacies was good to very good (10-20\%) with four pore types: (a) micro-inter-crystalline porosity; (b) micro-inter-granular porosity; (c) pinpoint micro-vuggy porosity; and (d) meso-channel and fracture porosity. Table 3 presents the mineralogy of the reservoir sequence in A1 well. Up to $40 \%$ of the most calcareous and calcareous to ferruginous arkose microfacies consisted of quartz with slightly weathered abundant feldspars. The feldspars were primarily microcline (11-20.4\%) and albite (17.2$24.7 \%$ ), and, at $1858.37 \mathrm{~m}$, labradorite constituted $25 \%$ of the rock. At shallow depths, anhydrite and gypsum were between $7.7 \%$ and $9.6 \%$ of the sample. Illite and dolomite were common at different depths but did not exceed $20 \%$ (Table 3 ).

Argillaceous Arkose Microfacies Argillaceous arkose was scattered through the entire sequence of the A1 well. It was composed of fine- to mediumgrained highly argillaceous and feldspathic sandstones, fining upward and with silty sandstone at the top. It was a poorly sorted, medium to coarse- grained sandstone with quartz and feldspars grains cemented with pseudo-sparite cement with clay patches, rare gypsum, and disseminated dolomite rhombs filling the pores (Fig. 3b, c). The porosity of the argillaceous arkose was $15-20 \%$, with highly porous streaks exceeding $25 \%$. Four types of pores were present: (a) micro-inter-crystalline porosity; (b) argillaceous-reduced, micro- to meso-vuggy porosity; (c) meso-channel porosity; and (d) microinter-granular porosity within the clay patches.

Calcareous Arkose Microfacies The calcareous arkose was present in different parts of the reservoir and was generally saturated with hydrocarbons. It is described as a dark brown friable, and highly weathered fining upward feldspathic sandstone with some ferruginous content. Petrographically, it was composed of poorly sorted fine to coarse, angular to sub-rounded quartz grains which sometimes are polycrystalline with wavy extinction and corroded surfaces. The quartz grains were cemented together by micrite to pseudo-sparite. Sometimes, the quartz grains were surrounded by iron oxide rims. In addition, some poorly sorted rock fragments and potash feldspars were present displaying parallel and cross-hatching extinction (Fig. 3d). Some clay and dolomitic patches as well as plant remains were rare. Porosity was good to excellent (20-30\%). Porosity is described as: (a) inter-granular; (b) micro-channel; (c) micro-fractures; and (d) vuggy.

\section{Analog A2 Well}

In analog A2 well, three microfacies based on their mineral composition and pore types were identified: (1) ferruginous arkose; (2) dolomitic arkose; and (3) argillaceous arkose.

Ferruginous Arkose Microfacies Ferruginous arkose was the most common microfacies in the A2 well, and consisted of poorly sorted fine to mediumgrained sandstones (Fig. 4a). It was a fine to medium, poorly sorted sandstone with rounded to angular quartz grains, in addition to fresh and altered albite and microcline (Fig. 4b). The quartz and feldspar grains were cemented with amorphous silica cement cementing the grains together in point contact. Some angular lithic fragments were also present in addition to iron oxide patches which can coat the cement and surrounding the grains with a very dark rim (Fig. 4a). This microfacies was subjected to extensive pyritization and sericitization and the sericite may migrate and cause pore filling, reducing porosity. The arkose 


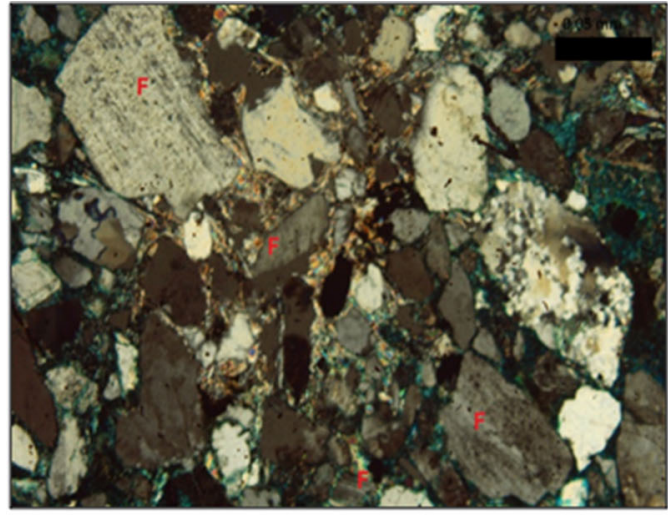

(a)

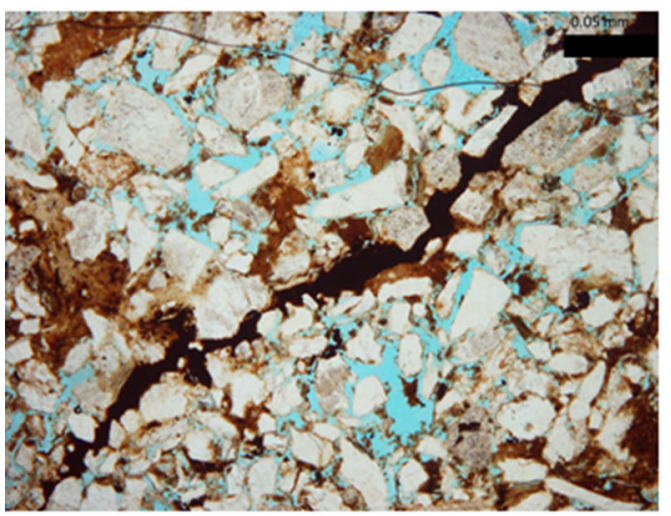

(c)

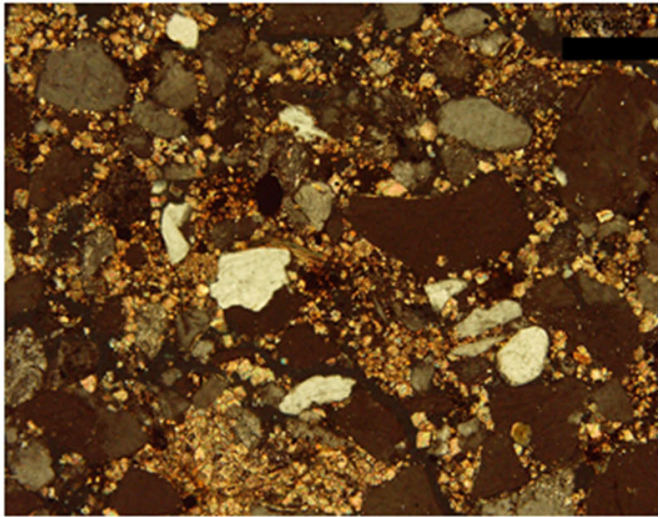

(b)

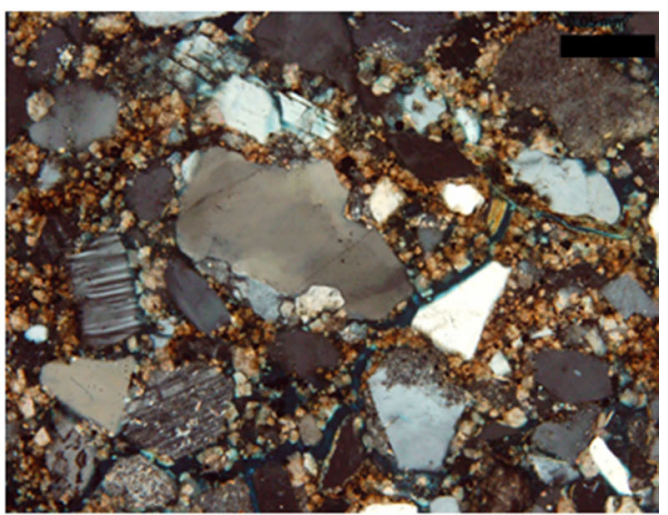

(d)

Figure 3. Photomicrographs show the dominant mineral composition and main components of the studied rock types in Hammam Faraun reservoir for the studied A1 well. (a) Coarse-grained potash feldspars and quartz grains cemented with highly ferruginated clay matrix, calcareous to ferruginated arkose microfacies, C.N. Scale bar is $0.05 \mathrm{~mm}$ in all photomicrograph, (b) Medium- to coarse-grained immature quartz grains and rock fragments cemented together with pseudo-sparite and common clay matrix, argillaceous arkose microfacies, C.N., and (c) Medium-grained quartz grains and rock fragments with very good inter-granular porosity (dyed blue) and meso-channel obliterated with clay matrix, argillaceous arkose microfacies, PPL., and (d) Ill-sorted fine to coarse grained quartz grains embedded in micritic cement, sometimes are dolomitic with very good intercrystalline pore spaces, calcareous arkose microfacies, C.N.

Table 3. XRD Results of A1 Well

\begin{tabular}{|c|c|c|c|c|c|c|c|c|c|}
\hline $\begin{array}{l}\text { Depth } \\
\text { (ft) }\end{array}$ & $\begin{array}{c}\text { Quartz } \\
(\%)\end{array}$ & $\begin{array}{l}\text { Microcline } \\
(\%)\end{array}$ & $\begin{array}{c}\text { Anhydrite } \\
(\%)\end{array}$ & $\begin{array}{c}\text { Gypsum } \\
(\%)\end{array}$ & $\begin{array}{l}\text { Illite } \\
(\%)\end{array}$ & $\begin{array}{l}\text { Albite } \\
(\%)\end{array}$ & $\begin{array}{l}\text { Dolomite } \\
(\%)\end{array}$ & $\begin{array}{c}\text { Labradorite } \\
(\%)\end{array}$ & $\begin{array}{c}\text { Calcite } \\
(\%)\end{array}$ \\
\hline 6045 & 56.6 & 11 & 4.7 & 3 & - & 24.7 & - & - & - \\
\hline 6097 & 53.8 & - & 2.4 & - & 7.2 & - & 11.6 & 25 & - \\
\hline 6110 & 50.4 & 14.1 & - & - & 4 & 20.5 & 3 & - & 8 \\
\hline 6151 & 55.6 & 20.4 & - & - & 2.2 & 18.5 & 3.3 & - & - \\
\hline 6185 & 53.9 & 19.6 & - & - & - & 17.2 & 9.3 & - & - \\
\hline
\end{tabular}

$1 \mathrm{ft}=0.3048 \mathrm{~m}$

was slightly ferruginous with clay patches scattered in the groundmass and altered and leached feldspars increase porosity. The porosity of the ferruginous arkose was characterized inter-granular porosity with some micro-fractures and vugs caused by dissolution and leaching of the feldspars.

Dolomitic Arkose Microfacies Dolomitic arkose was minor in the A3 well. It consisted of a few 


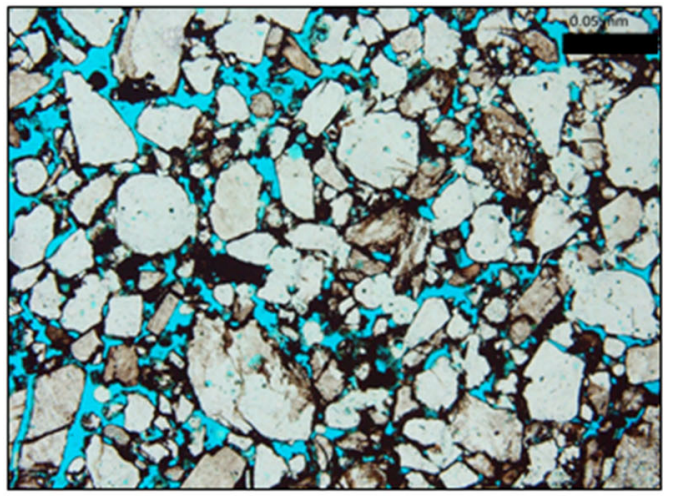

(a)

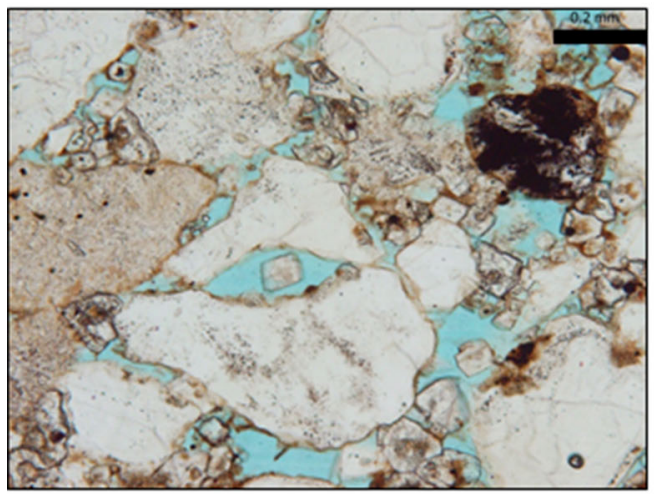

(c)

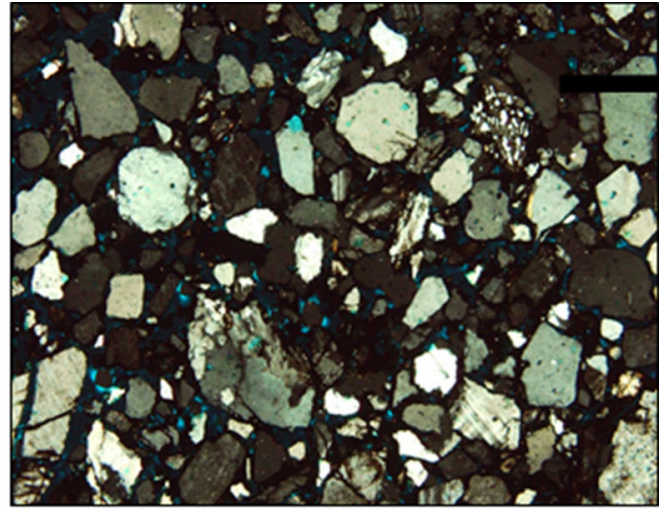

(b)

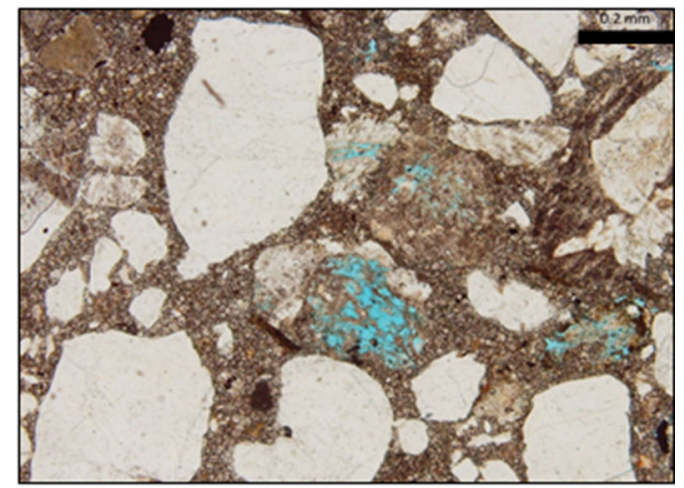

(d)

Figure 4. Photomicrographs show the mineral composition of Hammam Faraun reservoir for the analogue well A2. (a) Medium to coarse-grained, well-rounded to angular sand grains with very good inter-granular porosity. Note the presence of dark patches and rims surrounding the grains feldspathic quartz arenite microfacies, PPL, (b) Poly crystalline quartz grains with many feldspars represented by microcline of the cross-hatching lamination, dolomitic arkose microfacies, C.N., (c) Coarse to medium grained quartz grains and altered feldspars with very good inter-granular porosity. Note the presence of some well-developed dolomite rhombs, dolomitic feldspathic quartz arenite microfacies, PPL, and (d) coarse to medium-grained with dark brown clay patches and iron oxides with very good inter-granular and matrix porosity, feldspathic quartz arenite microfacies, PPL. Scale bar is $0.05 \mathrm{~mm}$ in (a) and (b) photomicrograph, while in (c) and (d) it is $0.02 \mathrm{~mm}$.

streaks scattered through the reservoir. It was composed of coarse- to medium-grained quartz grains and coarse feldspars which are frequently altered into scattered brown clay patches (Fig. 4c). There were at least two generations of dolomite crystals, well-developed clear rhombs and relatively fine, zoned crystals. Porosity was good to very good (20$25 \%$ ), and porosity types included (a) macro- and micro-inter-granular, and (b) vuggy.

Argillaceous Arkose Microfacies This microfacies was common in the A2 analog well. The arkose was a poorly sorted, very fine to coarse quartz grained sandstone with abundant highly altered feldspar. The feldspars relics floated in micro-sparite, amorphous silica, and clay patches (Fig. 4d). The grain surfaces were highly corroded and altered by the invading solutions (Fig. 4d). Some dolomite rhombs were scattered in the matrix with extensive pyritization and sericitization resulting in moderately reduced porosity (10-20\%). Porosity types included (a) macro- and micro-inter-granular; (b) micro-fractures and channels; and (3) inter-crystalline.

\section{Reservoir Characterization and Rock Typing}

\section{Petrophysical Data Log Plot}

Figure 5 compares the dominant reservoir characteristics of the A1 well with the analog A2 
well. The gamma ray (GR) in A1 well has values between 25 and 125 API with low values (25 API) in the middle of the sequence (1877.57-1889.76 m) and higher GR values near the bottom (100-125 API) suggesting that shales were present. However, the cross-over between the NPHI and RHOB logs indicates the presence of some sandstone thin beds in the top and middle parts with relatively consistent sonic and resistivity logs. In the A2 well, the lowermost parts of the studied Hammam Faraun sequence were composed generally of intercalations of shales and compacted thin beds of argillaceous sandstone with high GR (60-135 API), low DT (80$120 \mu \mathrm{m})$ and low resistivity values $(0.2-1.0$ O.m). High sonic and low resistivity values in the interval 1755.65-1798.32 m suggested water-saturated sandstone. Core data indicated the presence of a few streaks of sandstone having oil shows.

\section{Lithology Discrimination}

Bulk and grain density values were plotted (Fig. 6a, b) as a procedure for rock typing and lithological facies discrimination of the studied reservoir in both wells A1 and A2 (Tables 4, 5). Grain density for the studied sequence in the A1 well (at depth interval 1844.04-1927.86 m) ranged from 2.57 to $2.86 \mathrm{~g} / \mathrm{cm}^{3}$, but it was slightly lower in the A2 well (at depth interval 1712.98-1787.652 m) (2.46 to $2.72 \mathrm{~g} / \mathrm{cm}^{3}$, Table 4). Taking into consideration the core description data and the petrographical studies, four different reservoir rock types (RRTs) were recognized in the A1 well based on the bulk and grain density plot, these are (Fig. 6a, Table 4): (1) dolomitic limestones (RRT1); (2) calcareous to ferruginous arkose (RRT2); (3) argillaceous arkose (RRT3); and (4) calcareous arkose (RRT4). Three rock types were recognized in the A2 well based on the bulk and grain density plot, these are (Fig. 6b, Table 5): (1) ferruginous arkose (RRT1); (2) dolomitic arkose (RRT2); and (3) argillaceous arkose (RRT3).

\section{Quality Control on Core Data}

Bulk density for the A1 well was plotted versus the helium porosity of the studied core samples (Fig. 7a). This plot is generally presented as quality control for the measured data, where the bulk density-porosity relationships were highly reliable $\left(\mathrm{R}^{2} \geq\right.$
0.968, Fig. 7a) indicating that measured core data were highly reliable and systematic. The plot indicates that samples of the reservoir rock type no. 1 (RRT1) were relatively denser than the other rock samples, whereas the RRT3 were characterized by the lowest density values. This is in correspondence with that obtained from Figure $6 \mathrm{a}$ and the petrographical studies, which refer to sandy dolomitic limestone for the RRT1 samples and argillaceous arkose for RRT3 samples. This conclusion was also supported by the data presented in Table 4, where the average $\sigma_{\mathrm{b}}$ of RRT1 $=2.41 \mathrm{~g} / \mathrm{cm}^{3}$ while that for RRT3 $=2.05 \mathrm{~g} / \mathrm{cm}^{3}$. The same plot for the A2 well indicates reliable core data and denser composition for RRT2 samples (Fig. 7b). The multiplication factors of the $\sigma_{\mathrm{b}}-\varnothing_{\mathrm{He}}$ relationships for the A2 well were relatively similar (36.3-36.9) due to relative homogeneity in lithology, whereas for the A1 well they were slightly different (32.1-40.1), which is attributed to its heterogeneous nature.

\section{Heterogeneity of Hammam Faraun Reservoir}

Petrographical studies and the grain and bulk density plots support the conclusion that the mineral composition of the reservoir sequence in the A1 well was different from that of the A2 well. To better understand the inefficiency of the waterflooding in the A1 well, it is important to consider the heterogeneity of the flow capacity. Permeability is a direct measure for the flow capacity, through the entire reservoir sequence and can be measured using Dykstra-Parsons plot (1950). This plot has been recommended by El Sharawy and Nabawy (2019) to predict the efficiency of the waterflooding as a hydrocarbon secondary recovery tool. Permeability $(k)$ is plotted as a function of its cumulative frequency and then $k$ is calculated at both 50 and $84.1 \%\left(k_{50}, k_{84.1}\right)$ (Fig. 8). Heterogeneity of permeability $(V)$ and therefore heterogeneity of the flow capacity within the reservoir can be then calculated using the following equation.

$$
V=\left(k_{50}-k_{84.1}\right) / k_{50},
$$

Permeability is then ranked as follows El Sharawy and Nabawy (2019): (1) extremely heterogeneous reservoir $(0.75<V \leq 1.0)$; (2) highly heterogeneous reservoir $(0.50<V \leq 0.75)$; (3) moderately heterogeneous/homogeneous reservoir $(0.25<V \leq 0.50)$; (4) slightly heterogeneous/ho- 


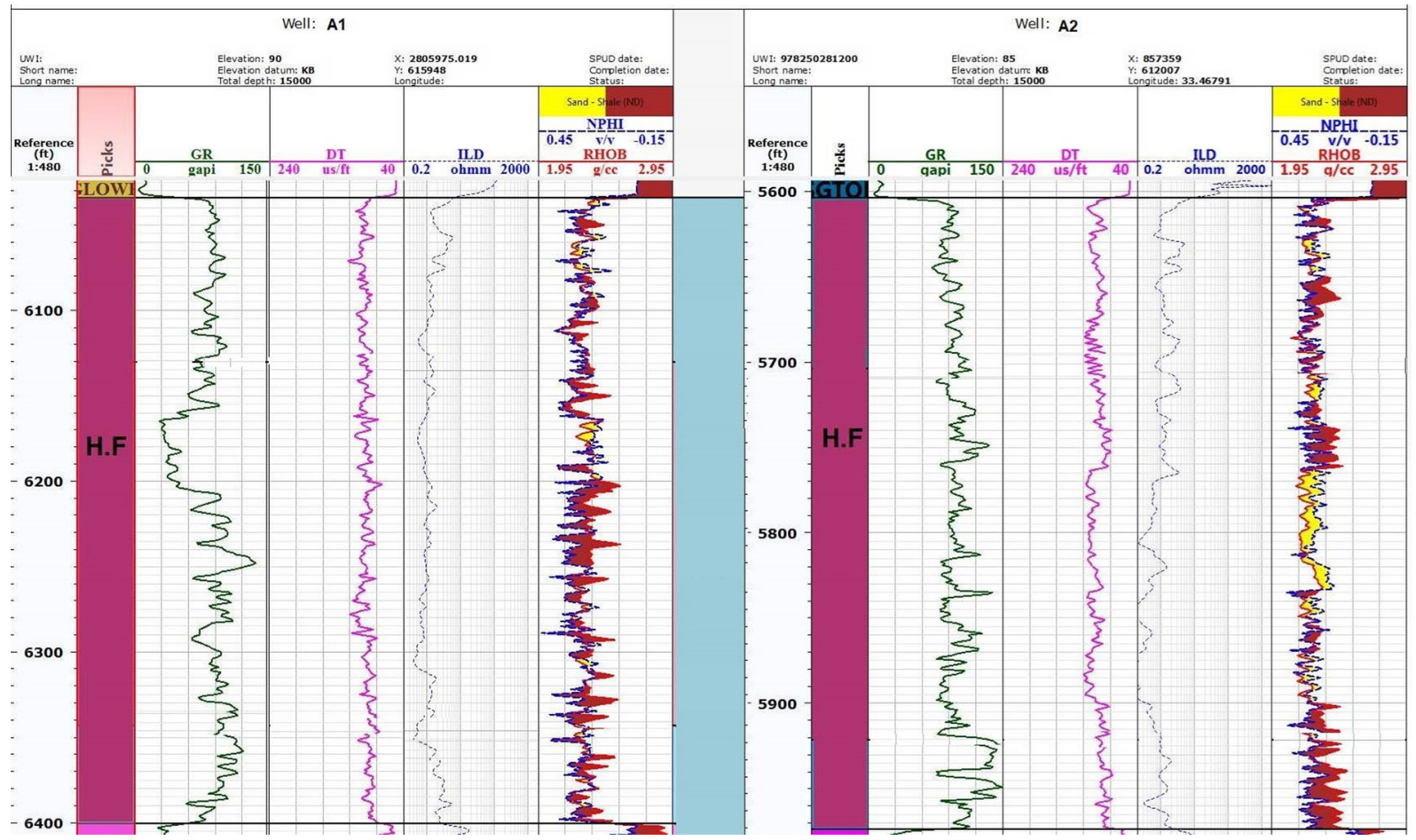

Figure 5. Vertical matching of the petrophysical data assigned for Hammam Faraun reservoir at the studied A1 well and the analogue A2 well.

mogeneous reservoir $(0.10<V \leq 0.25)$; and (5) homogeneous reservoir $(0.0<V \leq 0.10)$.

Therefore, applying this procedure indicates that Hammam Faraun reservoir is an extremely heterogeneous reservoir in both the A1 well and the analog A2 well, where $V$ is more than 0.75 (Fig. 8). Heterogeneity in the Hammam Faraun reservoir was generally attributed to varying lithology and diagenetic factors including overload pressure, cementation (by micro-sparite, silica and dolomicrite), dissolution, and leaching, feldspar alteration and authigenic pyrite, sericite and clay minerals.

\section{Implementation of Porosity on Fluid Transport}

Migration and fluid flow through the pore space of reservoir rocks is represented by the permeability values in both the vertical $\left(k_{\mathrm{V}}\right)$ and horizontal $\left(k_{\mathrm{H}}\right)$ directions. Permeability is a function of connectivity, pore volume, and pore size distribution (Desbois et al. 2011; Anovitz et al. 2013; Anovitz and Cole 2015; Nabawy 2018; Nabawy et al. 2018a, b). The anisotropy of pore structure can be seen in plots of the horizontal and vertical permeability versus porosity (Fig. 9). The plot of the horizontal and vertical permeability versus the porosity of the cored samples in the A1 well shows no consistency. Therefore, it was not considered an effective tool to model these parameters for further prediction of the different rock types. In the A2 well, the horizontal and vertical permeability as a function of porosity plot is more systematic (Fig. 10) than in the A1 well.

Therefore, horizontal permeability-porosity relationship in A1 well can be modeled in the form of exponential empirical models of moderate reliability $\left(0.506 \leq R^{2} \leq 0.564\right)$ due to the highly heterogeneous nature of Hammam Faraun reservoir (Fig. 10a). In addition, plotting the vertical permeability for this well as a function of porosity can be also modeled with moderate reliable relationships $\left(0.545 \leq R^{2} \leq 0.773\right.$, Fig. 10b). Horizontal permeability of RRT2 samples cannot be related to the measured porosity in a reliable relationship, whereas its vertical permeability can be modeled to porosity with good reliability $\left(R^{2}=0.773\right.$, Fig. 10b). This may be explained by the presence of some micro-fracture systems in these rock types that caused more con- 

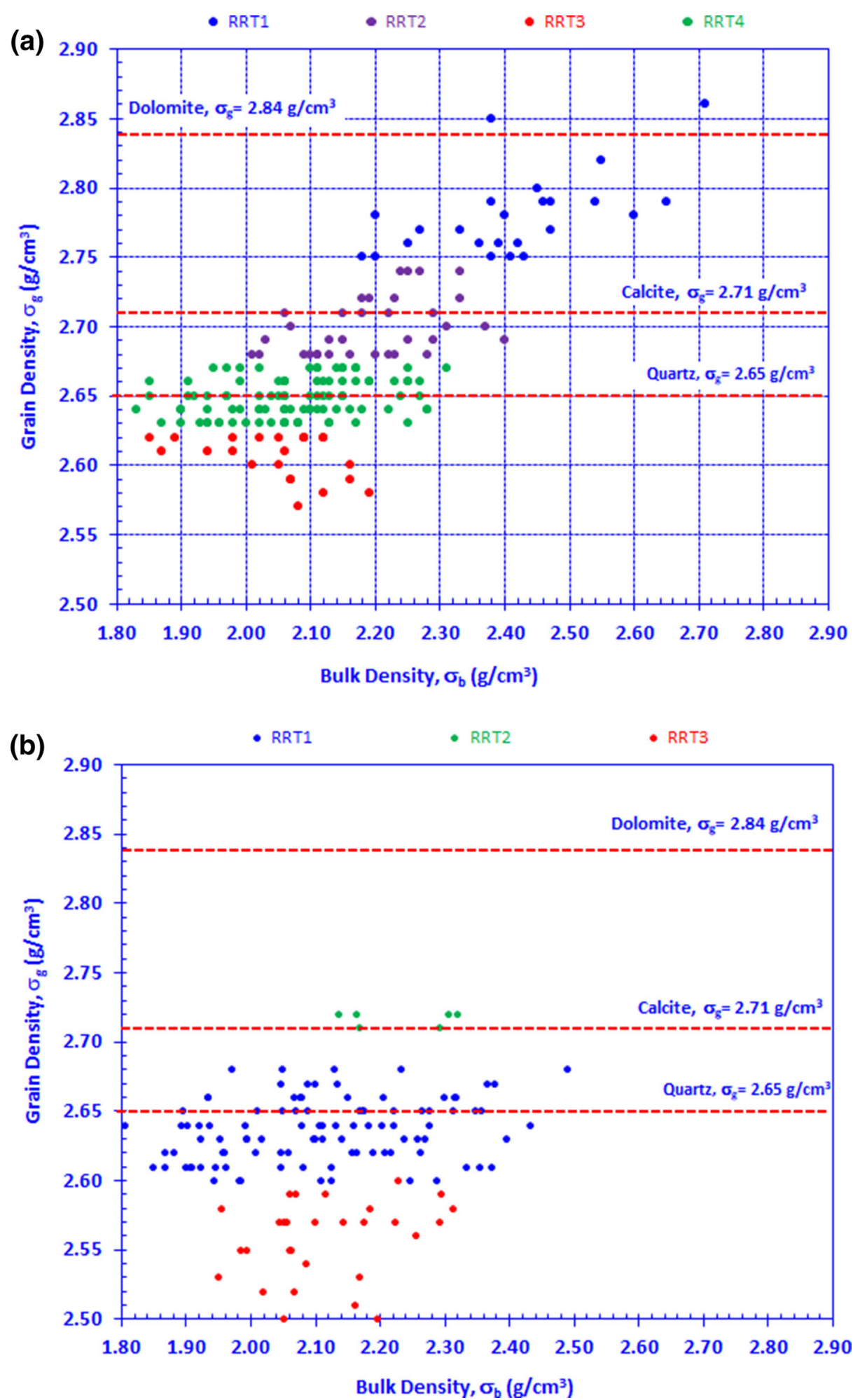

Figure 6. Plotting the bulk density as a function of the grain density for the Hammam Faraun samples in wells A1 and A2. 
Table 4. Petrophysical Conventional Core Data for the Studied Hammam Faraun Reservoir, A1 Well

\begin{tabular}{|c|c|c|c|c|c|c|c|c|c|c|c|c|c|c|}
\hline \multirow{2}{*}{$\begin{array}{l}\text { RRTs } \\
\begin{array}{l}\text { RRT1 (sandy dolomitic } \\
\text { limestones) }\end{array}\end{array}$} & \multicolumn{2}{|c|}{ S. no. } & \multirow{2}{*}{$\begin{array}{c}\begin{array}{c}k_{\mathrm{H}} \\
(\mathrm{md})\end{array} \\
0.01\end{array}$} & \multirow{2}{*}{$\begin{array}{c}\begin{array}{c}k_{\mathrm{V}} \\
(\mathrm{md})\end{array} \\
0.00\end{array}$} & \multirow{2}{*}{$\begin{array}{c}\lambda_{k} \\
0.00 \\
0.00\end{array}$} & \multirow{2}{*}{ 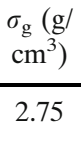 } & \multirow{2}{*}{ 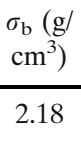 } & \multirow{2}{*}{$\begin{array}{c}\varnothing_{\mathrm{He}} \\
(\%)\end{array}$} & \multirow{2}{*}{$\begin{array}{l}\varnothing_{\mathrm{FS}} \\
(\%)\end{array}$} & \multirow{2}{*}{$\begin{array}{c}\begin{array}{c}S_{\mathrm{o}} \\
(\%)\end{array} \\
0.00\end{array}$} & \multirow{2}{*}{$\begin{array}{c}\begin{array}{c}S_{\mathrm{w}} \\
(\%)\end{array} \\
35.5\end{array}$} & \multirow{2}{*}{$\begin{array}{c}\text { RQI } \\
(\mu \mathrm{m})\end{array}$} & \multirow{2}{*}{$\begin{array}{l}\text { NPI } \\
0.00 \\
0.05\end{array}$} & \multirow{2}{*}{$\begin{array}{r}\text { FZI } \\
(\mu \mathrm{m})\end{array}$} \\
\hline & 24 & Min. & & & & & & & & & & & & \\
\hline & & Max. & 799.0 & 37.0 & 123.3 & 2.86 & 2.71 & 20.9 & 27.7 & 41.0 & 97.6 & 2.31 & 0.26 & 18.78 \\
\hline & & Avg. & 107.6 & 2.82 & 11.7 & 2.78 & 2.41 & 13.3 & 14.4 & 5.08 & 82.5 & 0.58 & 0.16 & 4.20 \\
\hline \multirow{3}{*}{$\begin{array}{l}\text { RRT2 (calcareous to fer- } \\
\text { ruginated arkose) }\end{array}$} & 34 & Min. & 0.87 & 0.01 & 0.40 & 2.68 & 2.01 & 10.7 & 6.40 & 0.00 & 60.3 & 0.08 & 0.12 & 0.29 \\
\hline & & Max. & 252.0 & 168.0 & 3.90 & 2.74 & 2.40 & 25.0 & 26.9 & 19.4 & 96.3 & 1.17 & 0.33 & 5.25 \\
\hline & & Avg. & 32.2 & 14.8 & 3.22 & 2.70 & 2.19 & 18.8 & 17.9 & 1.57 & 84.4 & 0.34 & 0.23 & 1.52 \\
\hline \multirow[t]{3}{*}{ RRT3 (argillaceous arkose) } & 23 & Min. & 0.56 & 0.20 & 0.58 & 2.57 & 1.85 & 15.3 & 14.5 & 0.00 & 37.3 & 0.06 & 0.18 & 0.28 \\
\hline & & Max. & 485.0 & 401.0 & 15.7 & 2.62 & 2.19 & 29.4 & 28.3 & 35.5 & 95.9 & 1.28 & 0.42 & 4.32 \\
\hline & & Avg. & 100.3 & 91.4 & 1.80 & 2.61 & 2.05 & 21.5 & 21.9 & 11.4 & 67.8 & 0.50 & 0.28 & 1.70 \\
\hline \multirow[t]{3}{*}{ RRT4 (calcareous arkose) } & 95 & Min. & 0.64 & 0.02 & 0.454 & 2.63 & 1.83 & 13.5 & 8.20 & 0.00 & 21.9 & 0.05 & 0.16 & 0.18 \\
\hline & & Max. & 413.0 & 264.0 & 164.3 & 2.67 & 2.31 & 30.6 & 29.8 & 38.1 & 97.8 & 1.23 & 0.44 & 3.67 \\
\hline & & Avg. & 61.1 & 43.5 & 3.73 & 2.65 & 2.07 & 21.7 & 20.6 & 6.94 & 74.1 & 0.42 & 0.28 & 1.40 \\
\hline
\end{tabular}

$\sigma_{\mathrm{b}}$ and $\sigma_{\mathrm{g}}$ are bulk and grain densities, respectively. $\varnothing_{\mathrm{He}}$ and $\varnothing_{\mathrm{SF}}$ are measured porosity using helium injection and summation fluids technique, respectively. $k_{\mathrm{H}}$ and $k_{\mathrm{V}}$ are measured permeability in the horizontal and vertical directions, respectively. $\lambda_{k}$ is anisotropy of permeability. $S_{\mathrm{o}}$ and $S_{\mathrm{w}}$ are measured oil and water saturations, respectively

$R Q I$ Reservoir quality index, FZI Flow zone indicator

Table 5. Petrophysical Routine Core Data for the Studied Hammam Faraun Reservoir, A2 Well

\begin{tabular}{|c|c|c|c|c|c|c|c|c|c|c|c|c|c|c|}
\hline RRTs & & no. & $\begin{array}{c}k_{\mathrm{H}} \\
(\mathrm{md})\end{array}$ & $\begin{array}{c}k_{\mathrm{V}} \\
(\mathrm{md})\end{array}$ & $\begin{array}{c}\lambda_{\mathrm{k}} \\
0.00\end{array}$ & $\begin{array}{l}\sigma_{\mathrm{g}}(\mathrm{g} / \\
\left.\mathrm{cm}^{3}\right)\end{array}$ & $\begin{array}{l}\sigma_{\mathrm{b}}(\mathrm{g} / \\
\left.\mathrm{cm}^{3}\right)\end{array}$ & $\begin{array}{l}\varnothing_{\mathrm{He}} \\
(\%)\end{array}$ & $\begin{array}{l}\varnothing_{\mathrm{FS}} \\
(\%)\end{array}$ & $\begin{array}{l}S_{\mathrm{o}} \\
(\%)\end{array}$ & $\begin{array}{c}S_{\mathrm{w}} \\
(\%)\end{array}$ & $\begin{array}{l}\text { RQI } \\
(\mu \mathrm{m})\end{array}$ & $\begin{array}{l}\text { NPI } \\
0.00\end{array}$ & $\begin{array}{l}\text { FZI } \\
(\mu \mathrm{m})\end{array}$ \\
\hline \multirow{3}{*}{$\begin{array}{l}\text { RRT1 (ferruginated } \\
\text { arkose) }\end{array}$} & 24 & Min. & 0.05 & 0.02 & 0.08 & 2.600 & 1.752 & 7.10 & 7.9 & 1.10 & 11.0 & 0.03 & 0.076 & 0.171 \\
\hline & & Max. & 2513 & 2031 & 17.8 & 2.680 & 2.490 & 33.4 & 38.7 & 77.5 & 93.5 & 3.02 & 0.502 & 8.078 \\
\hline & & Avg. & 247.1 & 202.3 & 2.27 & 2.637 & 2.094 & 20.6 & 22.8 & 35.65 & 49.24 & 0.69 & 0.267 & 2.291 \\
\hline \multirow{3}{*}{$\begin{array}{l}\text { RRT2 (dolomitic } \\
\text { arkose) }\end{array}$} & 34 & Min. & 0.19 & 0.09 & 0.05 & 2.710 & 2.135 & 14.7 & 13.1 & 6.0 & 13.3 & 0.03 & 0.172 & 0.121 \\
\hline & & Max. & 28.5 & 963 & 2.24 & 2.720 & 2.320 & 21.5 & 21.0 & 66.9 & 82. & 0.38 & 0.274 & 1.499 \\
\hline & & Avg. & 5.33 & 165.5 & 1.00 & 2.717 & 2.231 & 17.9 & 19.1 & 29.18 & 55.20 & 0.11 & 0.219 & 0.467 \\
\hline \multirow{3}{*}{$\begin{array}{l}\text { RRT3 (argillaceous } \\
\text { arkose) }\end{array}$} & 23 & Min. & 0.20 & 0.01 & 0.39 & 2.460 & 1.95 & 10.4 & 5.00 & 4.10 & 18.1 & 0.04 & 0.120 & 0.20 \\
\hline & & Max. & 221.0 & 308 & 18.7 & 2.600 & 2.31 & 24.3 & 26.7 & 70.6 & 93.1 & 0.95 & 0.320 & 3.23 \\
\hline & & Avg. & 18.2 & 15.03 & 3.35 & 2.552 & 2.11 & 17.2 & 19.3 & 16.89 & 70.89 & 0.22 & 0.212 & 0.980 \\
\hline
\end{tabular}

Symbols the same as in Table 4

sistent permeability in the vertical direction $\left(k_{\mathrm{V}}\right)$. Porosity and permeability cutoff values indicate that most of the studied samples are prospective as porous and permeable in both the A1 well (Fig. 9a) and the analog A2 well (RRT1, RRT3 samples, Fig. 10a).

Plotting horizontal permeability versus the vertical permeability shows that the horizontal and vertical permeability is different than the bulk permeability of the reservoir in the studied two wells (Fig. 11). Horizontal permeability was higher than vertical permeability in the A1 well indicating the dominance of depositional pore fabrics and shale streaks (Fig. 10a). In the A2 well, the vertical permeability was higher than the horizontal permeability indicating the dominance of secondary pore fabrics due to the presence of micro-fracture systems. For RRT2 samples, it seems that the studied samples were characterized by the presence of both the depositional and secondary pore fabrics in the different samples (Fig. 10b). Therefore, in addition to the heterogeneous reservoir property that was indicated by high variation of permeability $(V)$ values in the studied reservoir, additional permeability anisotropy $\left(\lambda_{k}\right)$ was assigned for each sample due to the difference between the vertical and horizontal 


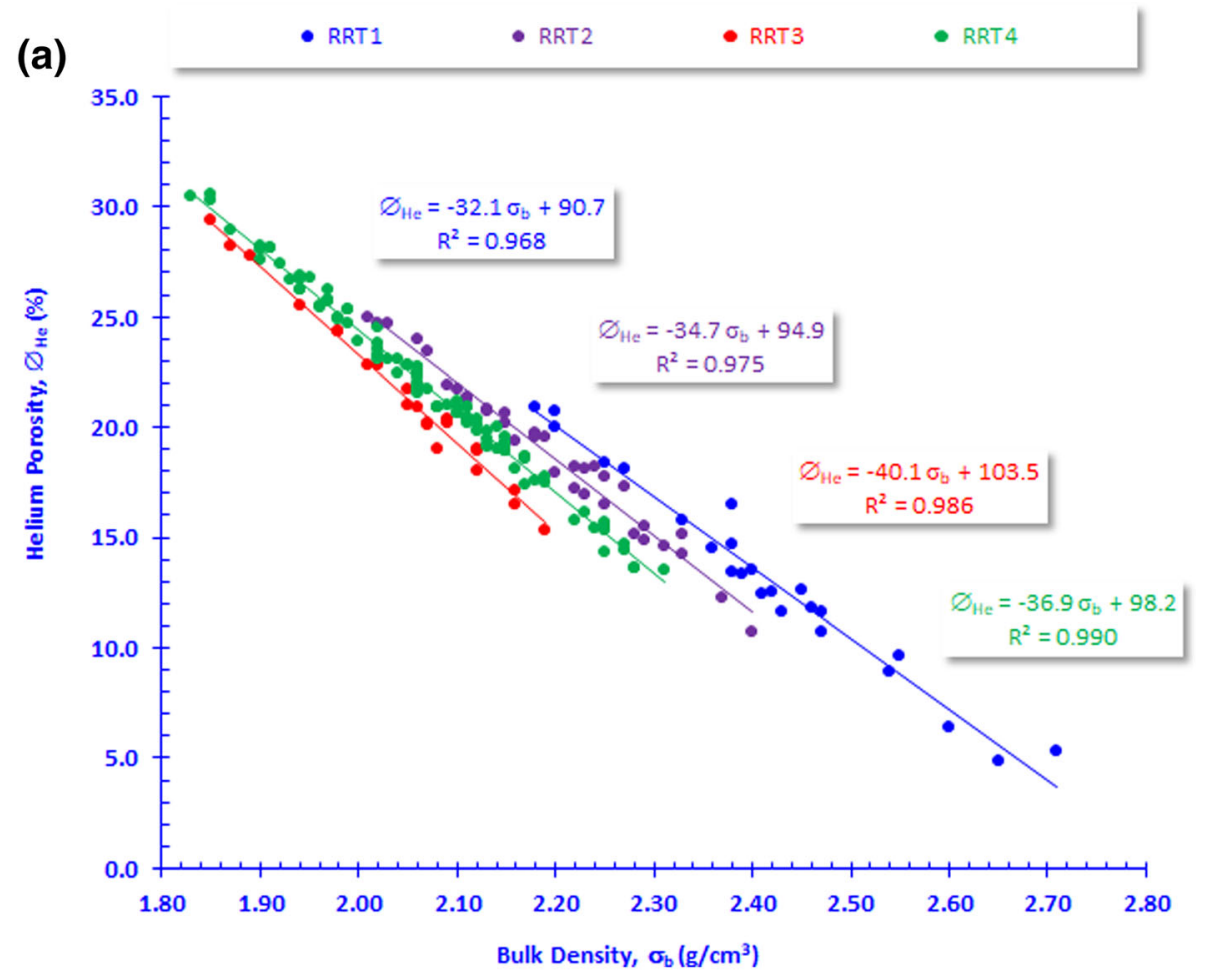

(b)

b)
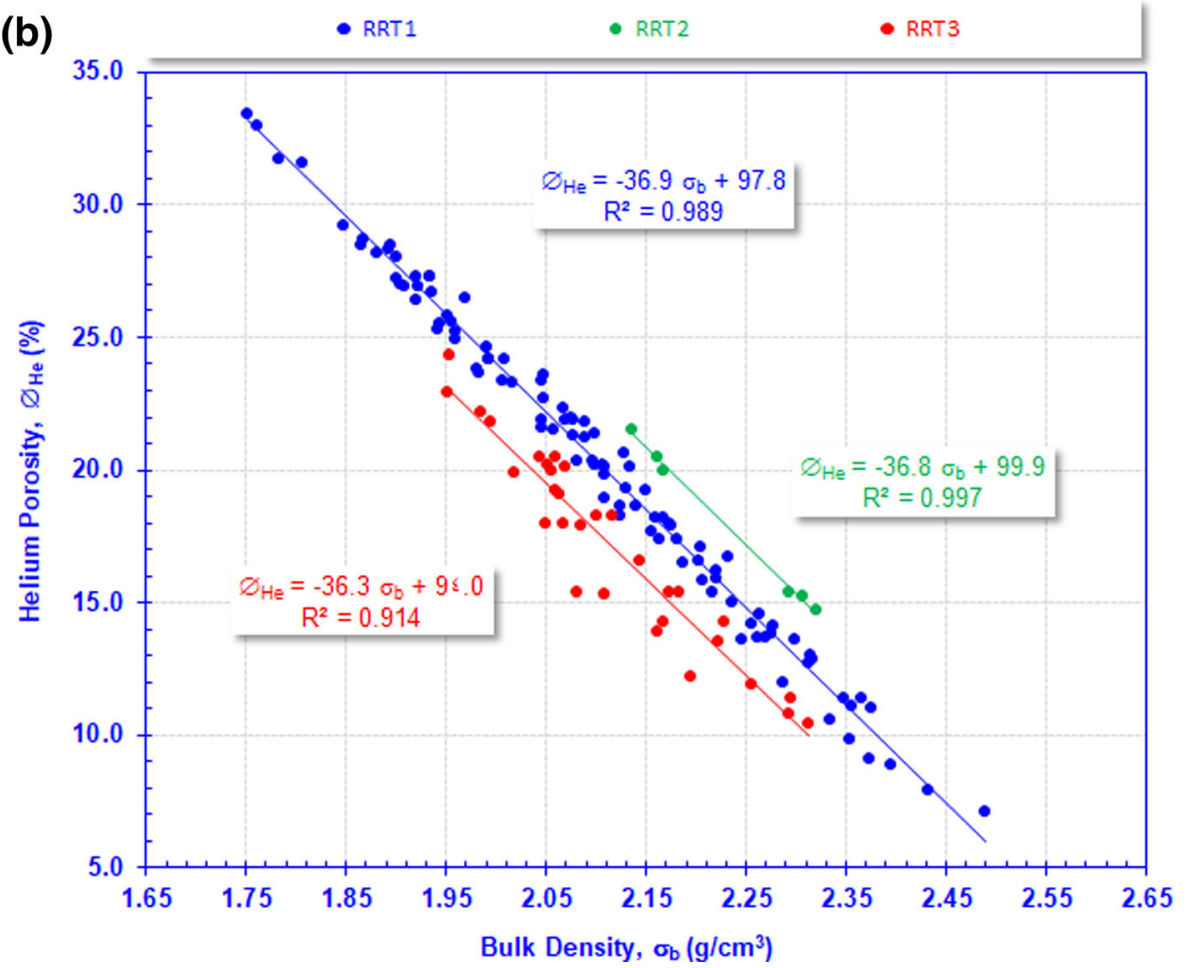

Figure 7. Plotting the bulk density $\left(\sigma_{\mathrm{b}}\right)$ values as a function of the helium porosity $\left(\varnothing_{\mathrm{He}}\right)$ for the Hammam Faraun reservoir in: (a) A1 well, and (b) A2 well. 


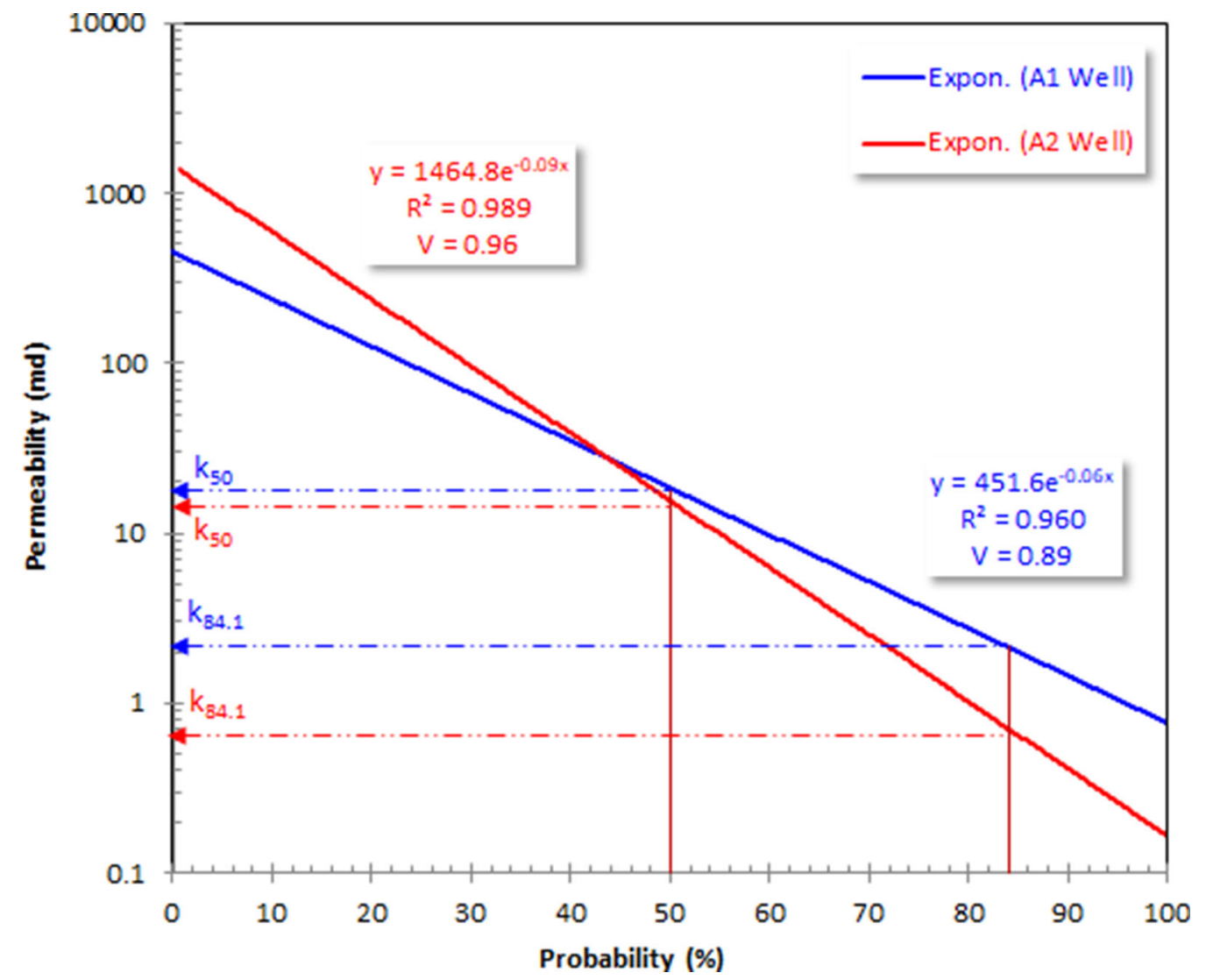

Figure 8. Checking the heterogeneity of the Hammam Faraun reservoir using the Dykstra-Parsons technique (1950) in the studied wells following El Sharawy and Nabawy (2019).

permeability values at the same depth. Following the anisotropy classification proposed by Nabawy et al. (2015), Nabawy and Géraud (2016), Nabawy and David (2016), the average permeability anisotropy $\left(\lambda_{k}\right)$ is described as moderate to extremely anisotropic $\left(1.80 \leq\right.$ average $\left.\lambda_{k} \leq 11.7\right)$ for the different rock types in the A1 well (Table 4). In the A2 well, the average permeability anisotropy values $\left(\lambda_{k}\right)$ were more consistent and less scattered $(1.0 \leq$ av. $\left.\lambda_{\mathrm{k}} \leq 3.35\right)$ than in the A1 well for the different rock types. In the A2 well, $\lambda_{\mathrm{k}}$ values were described as anisotropic to moderately anisotropic, and sometimes were highly anisotropic (Table 5).

\section{Implementation of Permeability to the Reservoir Quality Index ' $R Q I$ '}

The RQI is determined by porosity, permeability, and pore space connectivity. Because the $\varnothing$ -
$k_{\mathrm{V}}$ relationship of RRT1 and RRT2 samples was highly scattered, plotting the RQI as a function of both the horizontal and vertical permeability $\left(k_{\mathrm{H}}\right.$ and $k_{\mathrm{V}}$, respectively), indicates that RQI was controlled by horizontal permeability in the A1 well (Fig. 12). This could be explained by disturbance of the vertical permeability $k_{\mathrm{V}}$ values of RRT1 and RRT2 samples when plotted as a function of the RQI values and therefore cannot be modeled (Fig. 12). This may be attributed to the non-clastic nature of RRT1 samples and the presence of shale streaks (RRT1, RRT2) which significantly increased their permeability anisotropy values.

The RQI of the A2 well was controlled by horizontal permeability, not vertical permeability. Although there were vertical micro-fractures in this well, the RQI was primarily controlled by horizontal permeability (Fig. 13). Therefore, RQI values of both wells can be modeled as a function of horizontal permeability with high reliability $\left(0.997 \geq R^{2}\right.$ 
(a)

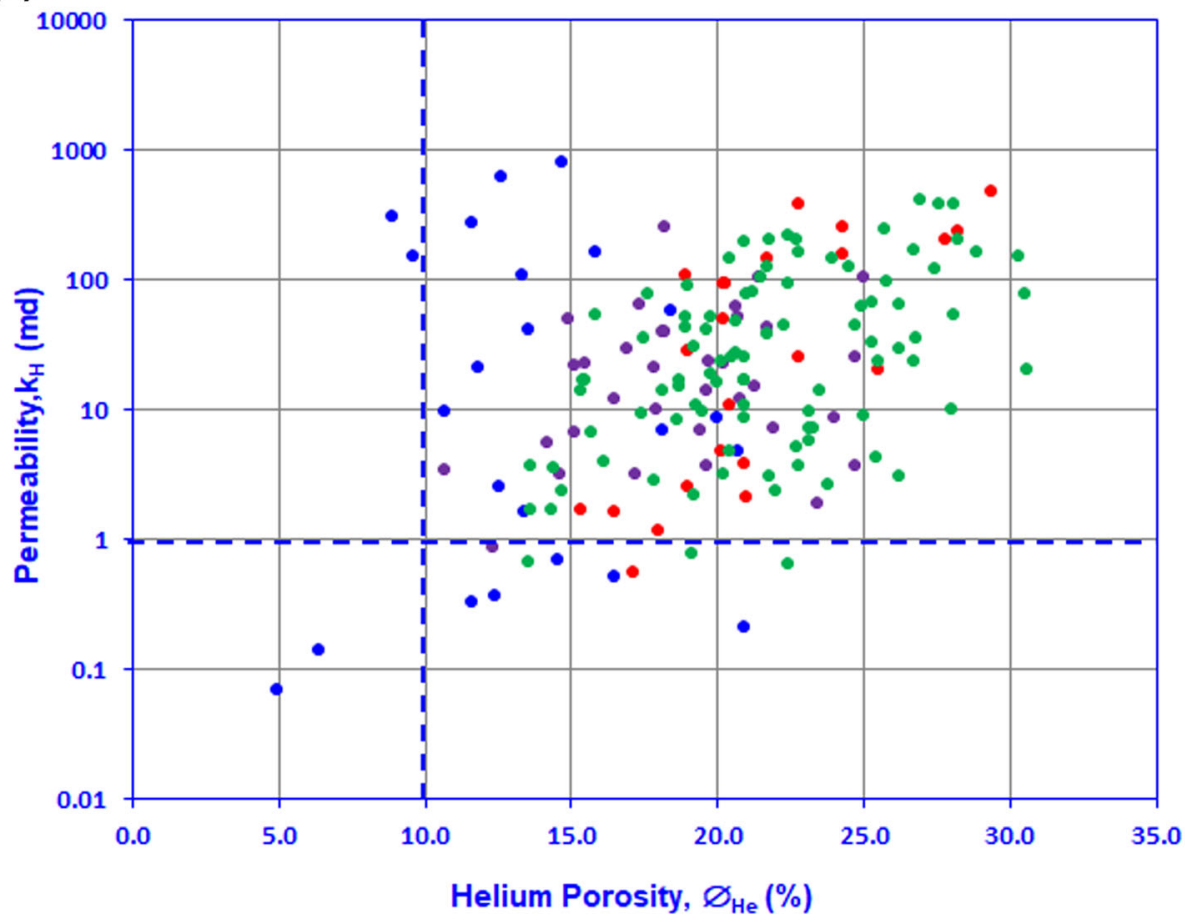

(b) $\quad$ - RRT1 $\quad$ RRT2 RRT3

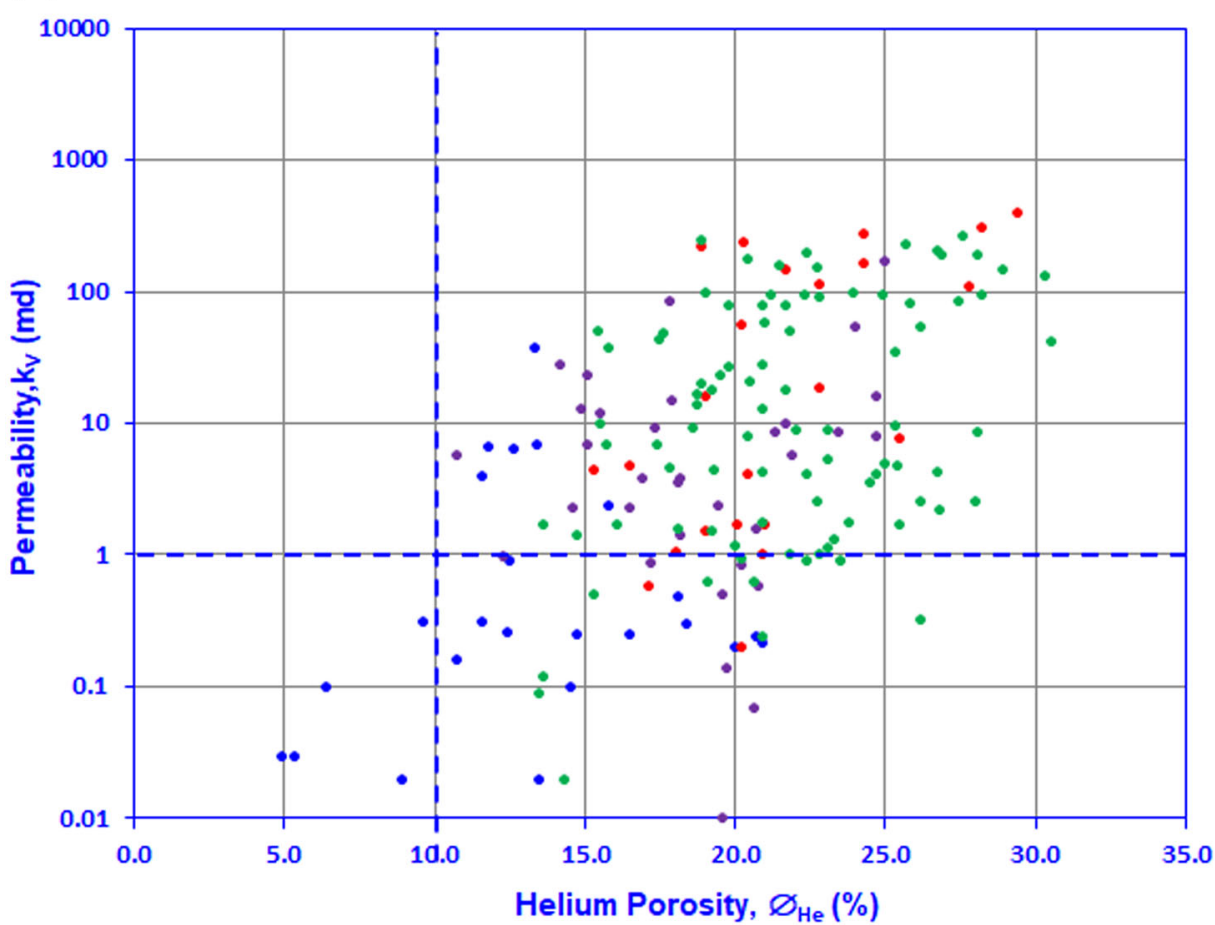

Figure 9. Plotting (a) the horizontal permeability ' $k_{\mathrm{H}}$ ', and (b) vertical permeability ' $k_{\mathrm{V}}$ ' as a function of the helium porosity $\left(\varnothing_{\mathrm{He}}\right)$ for the A1 well. 
(a)

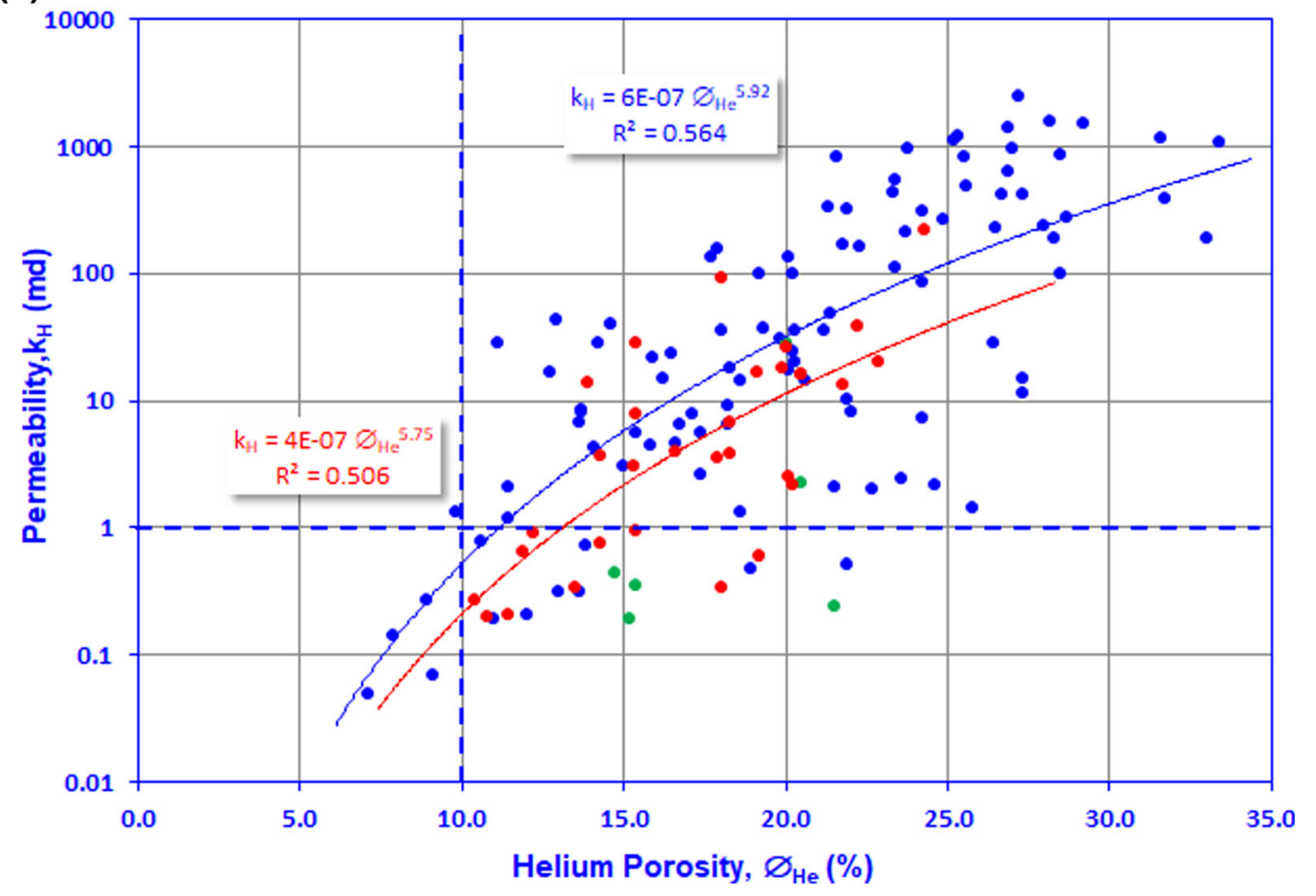

(b)

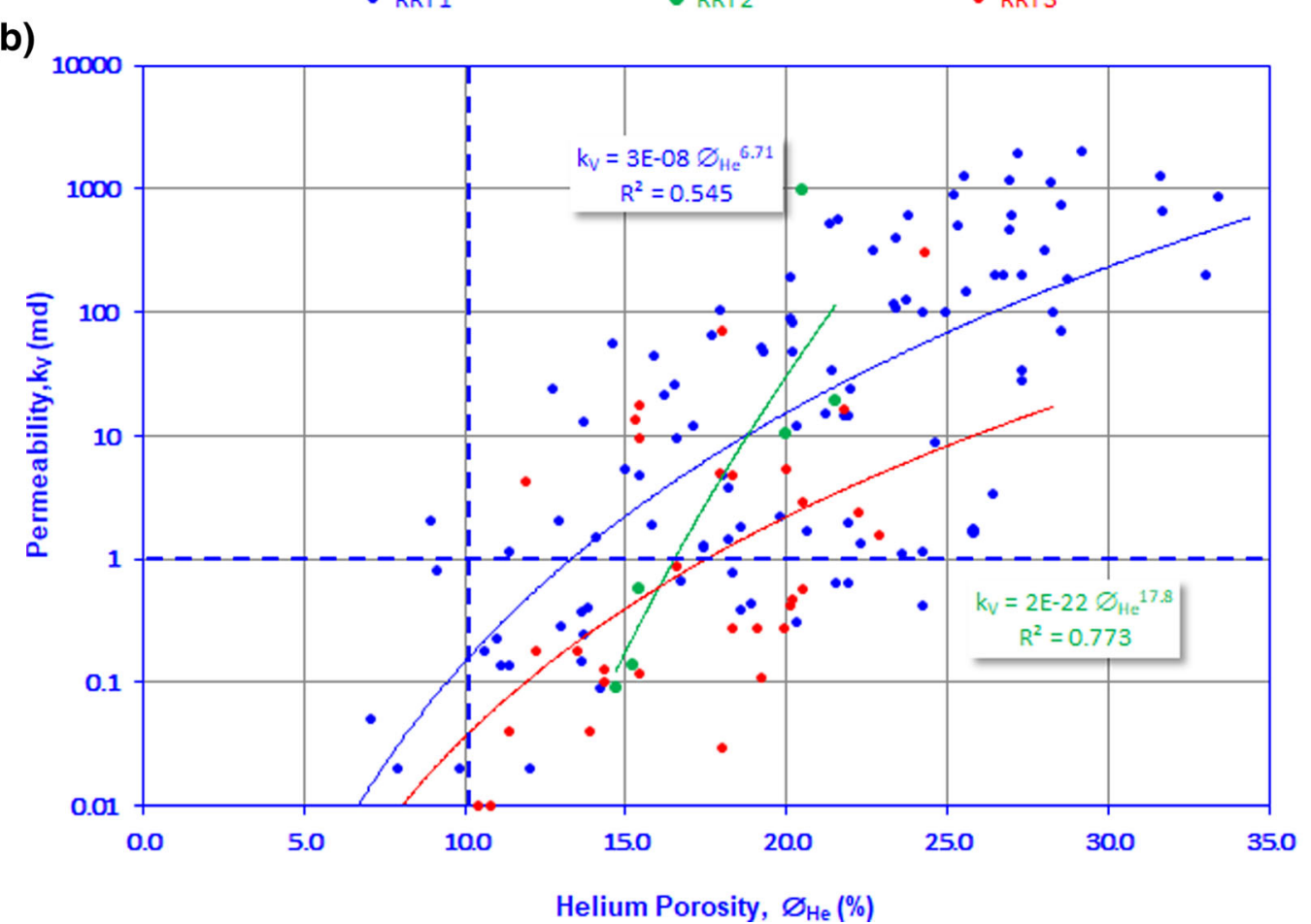

Figure 10. Plotting (a) the horizontal permeability $\left(k_{\mathrm{H}}\right)$, and $(\mathbf{b})$ the vertical permeability $\left(k_{\mathrm{V}}\right)$ as a function of helium porosity $\left(\varnothing_{\mathrm{He}}\right)$ for the A2 well. 
(a)

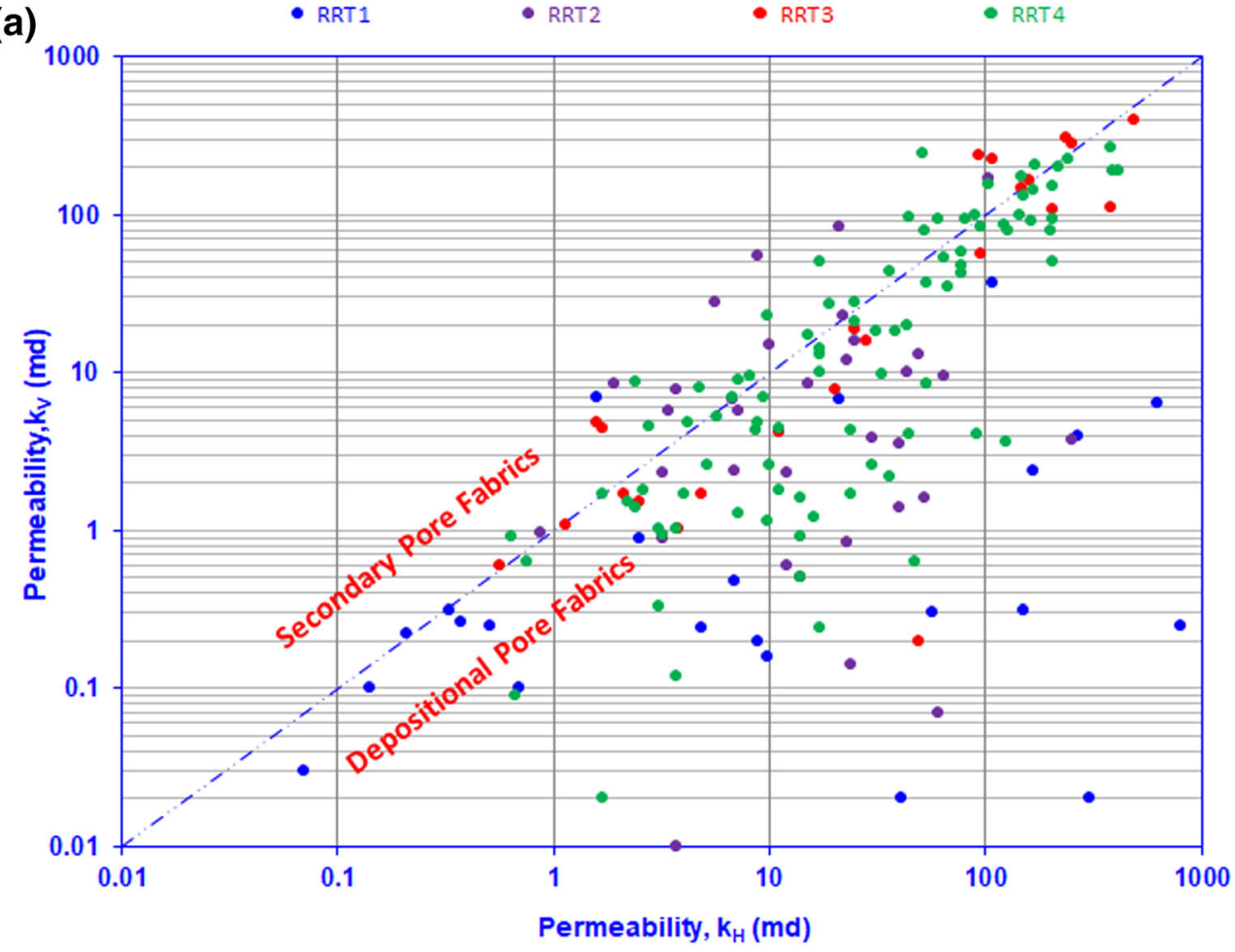

(b)

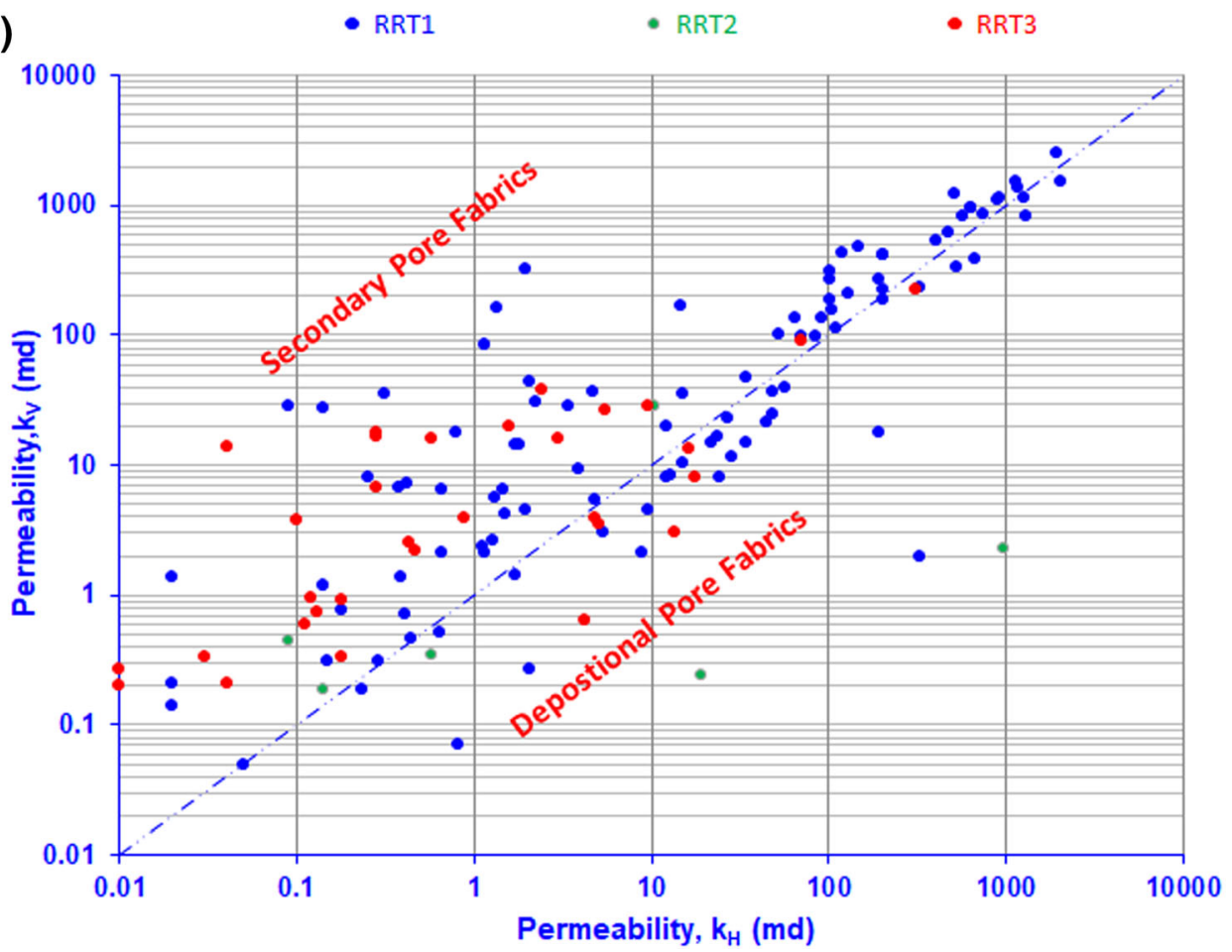

Figure 11. Plotting the vertical permeability $\left(k_{\mathrm{V}}\right)$ vs. horizontal permeability $\left(k_{\mathrm{H}}\right)$ for: (a) A1 well, and (b) A2 well. 
(a)

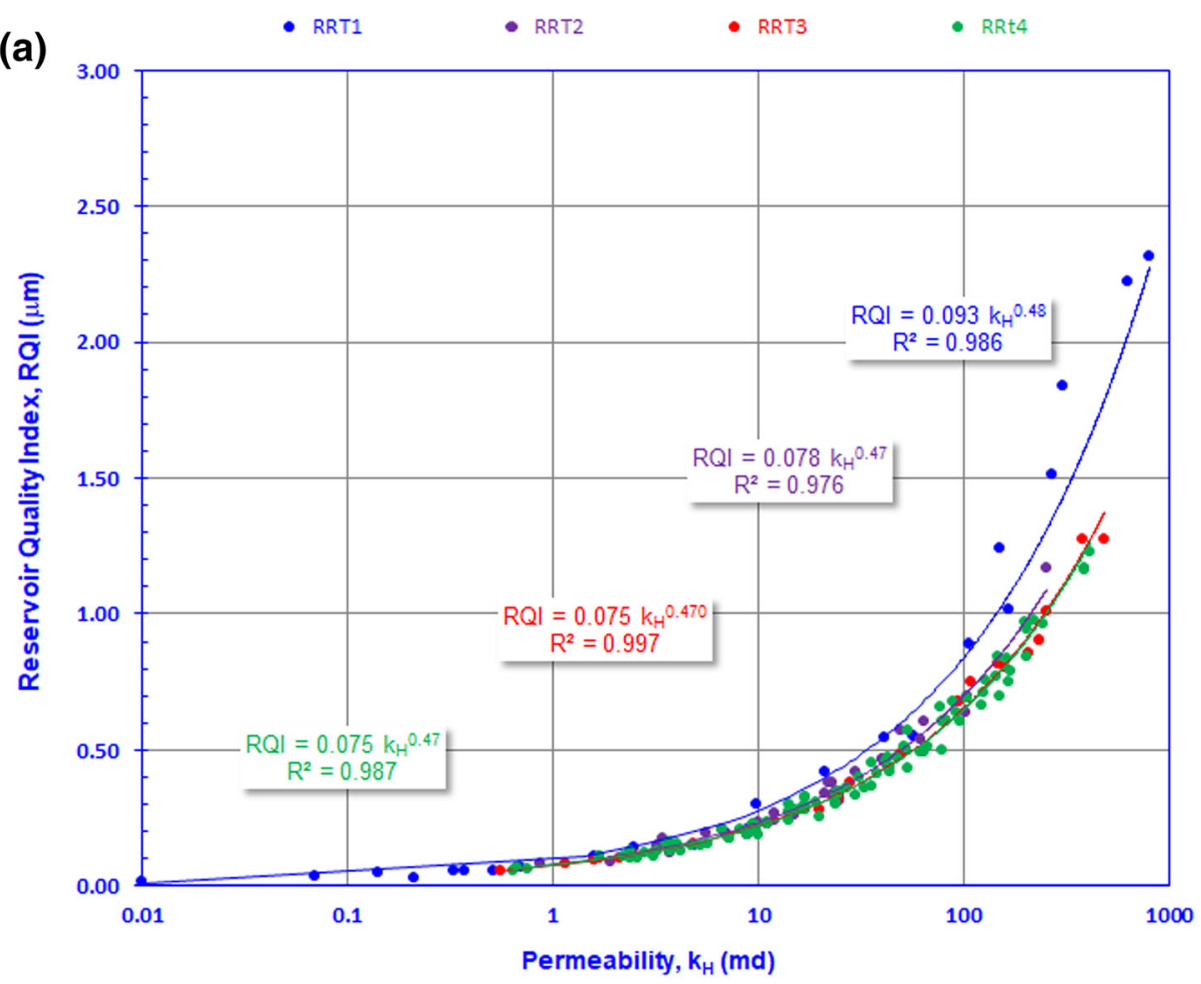

(b)
- RRT1
- RRt2
- RRT3
- RRT4

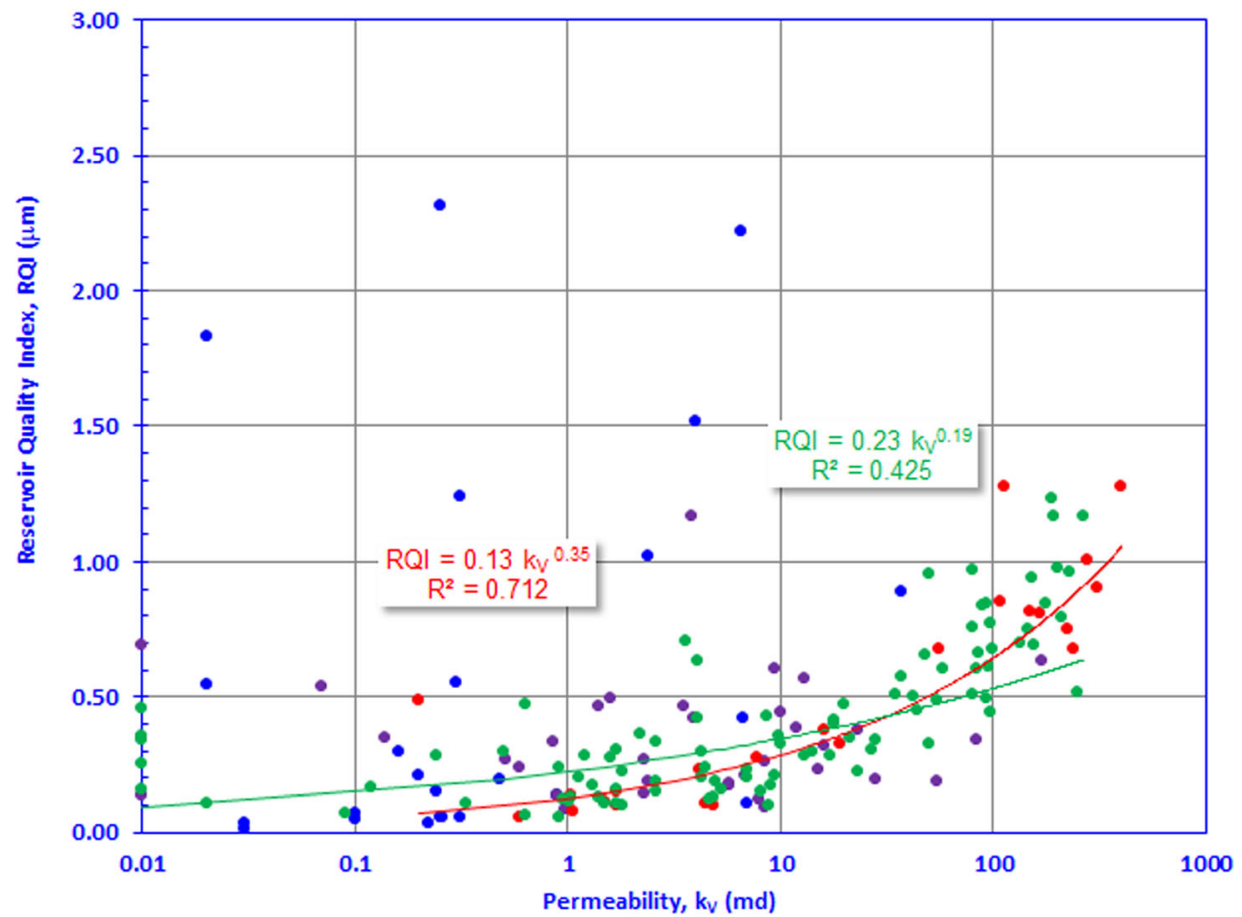

Figure 12. Plotting the reservoir quality index (RQI) vs.: (a) horizontal, and (b) vertical permeability for A1 well. 


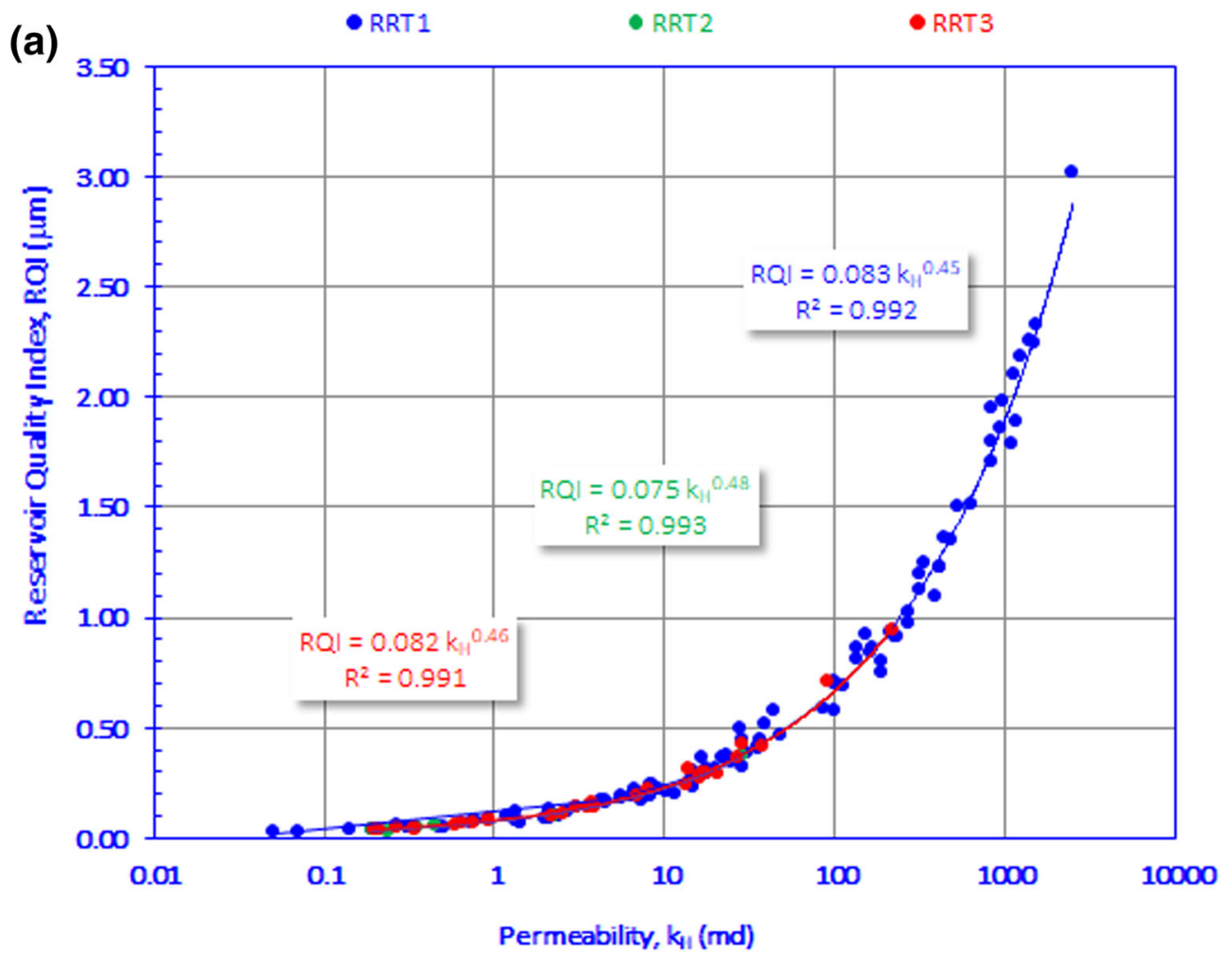

(b)

- RRT1

- RRT2

- RRT3

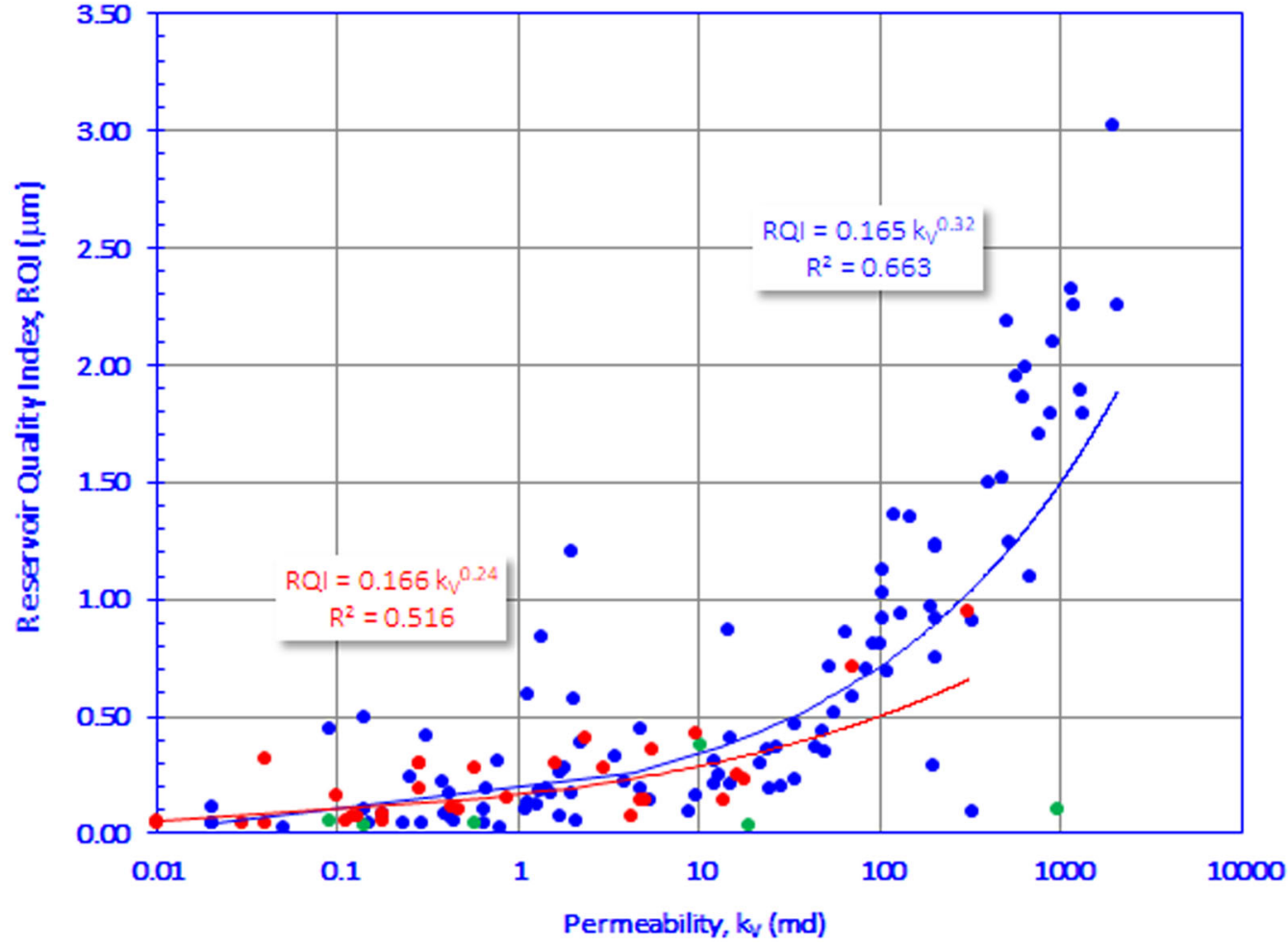

Figure 13. Plotting the reservoir quality index (RQI) vs.: (a) horizontal, and (b) vertical permeability for A2 well. 
$\geq 0.991$ ). Using the RQI classification introduced by Nabawy and Barakat (2017), the Hammam Faraun reservoirs were ranked as poor to fair reservoirs $(0.11<$ average $\mathrm{RQI}<0.69$, Tables 4,5$)$. Some prospective permeability streaks were assigned in both the A1 well (RQI up to $2.31 \mu \mathrm{m}$ ) and A2 well (RQI up to $3.02 \mu \mathrm{m}$ ). The poor to fair classification of this reservoir was attributed to its heterogeneous nature due to the presence of some highly prospective streaks and impervious streaks (Figs. 12, 13, Tables 4, 5).

\section{Estimation of Reservoir Quality Ranks}

Plotting FZI as a function of RQI can help to discriminate different reservoir zones and flow units (Figs. 14, 15). In the conductive zone intervals of the A1 well, many prospective zones were characterized by poor to very good RQI and poor to good FZI (Fig. 14a). In the A2 well, most samples of RRT1 and many samples of RRT3 were classified as conductive (Fig. 14b). This suggests that, although the Hammam Faraun reservoir is extremely heterogeneous, many intervals within the reservoir were classed as conductive reservoirs.

For reservoir discrimination into HFUs, RQI was plotted as a function of NPI and considering the FZI values for both wells. Figure 15 indicates that few samples of the A1 well represented poor to good HFUs (FZI $>5 \mu \mathrm{m})$ whereas the other samples indicated an impervious oil reservoir (Fig. 15a). For the A2 well, relatively few samples were impervious $(1.0 \leq$ FZI $\leq 10 \mu \mathrm{m}$, Fig. 15b). However, permeability and RQI values were still higher for the reservoir sequence in the A2 well (av. $k_{\mathrm{H}}=176.5$ $\mathrm{md}$, av. $\mathrm{RQI}=0.54 \mu \mathrm{m}$ ) than in the A1 well (av. $k_{\mathrm{H}}=67.3 \mathrm{md}$, av. $\mathrm{RQI}=0.44 \mu \mathrm{m}$ ), indicating much better quality of HFUs in the analog A2 well than in the A1 well.

\section{Reservoir Zonation into HFUs}

Reservoir zonation and discrimination into several HFUs is generally based on plotting the storage capacity (porosity), flow capacity (permeability), RQI, FZI, RPI, and fluids saturation as a function of depth (Fig. 16a, b). From this plot, the reservoir sequence in the A1 well can be discriminated into five HFUs with the best quality assigned for some streaks in the top of this sequence (HFU-5) and the basal parts (HFU-2). Taking into consideration the oil and water saturations, the top parts show good saturation of oil (HFU-4, HFU-5), and the oil-water contact was assigned at depth of $1859.28 \mathrm{~m}$, i.e., most of the sequence was saturated with water except for the topmost parts (Fig. 16a). The studied Hammam Faraun was generally waterwet, i.e., water occupied the micro-pore spaces and enforced the oil into the meso- and macro-pores (Nabawy and Barakat 2017). This may indicate that the largest pore sizes were assigned in the top of Hammam Faraun reservoir in the A1 well. This is supported by the dominant very good permeability values through the top, which was represented mostly by sandy dolomitic limestones (RRT1, av. $k_{\mathrm{H}}=107.6 \mathrm{md}$ ), and argillaceous arkose (RRT3, av. $k_{\mathrm{H}}=100.3 \mathrm{md}$ ) samples.

However, the studied sequence in the analog A2 well can be discriminated into three HFUs with $70 \%$ of the sequence characterized by good to very good quality, where some streaks (RRT1 and RRT3) were characterized by excellent permeability values more than 1000 md (Fig. 16b). In addition, some oil and water-bearing zones were encountered at different depths along the A2 well. This indicates the scattering of the macro- and meso-pore spaces along the entire sequence of the reservoir in the A2 well. Therefore, due to the pore size distribution and reservoir quality, waterflooding through the A2 well was efficient, distributed through the entire sequence, then through the A1 well, in which waterflooding was efficient only though the top.

\section{Reservoir Engineering Data}

In the following sections, the reservoir engineering parameters (Table 1) including pressures, production, temperature, perforated thickness, petrophysical parameters, and fluid parameters are discussed, integrated, and analyzed to get more information about the reservoir history and conditions in the A1 well.

\section{Engineering Parameters}

The El Morgan A1 well has been prepared as an oil producer and added to the producing wells in 1992 of 520 BOPD as a daily production rate and $5 \%$ water cut. The initial static petrophysical parameters of the A1 well were $23 \%$ porosity, 100 

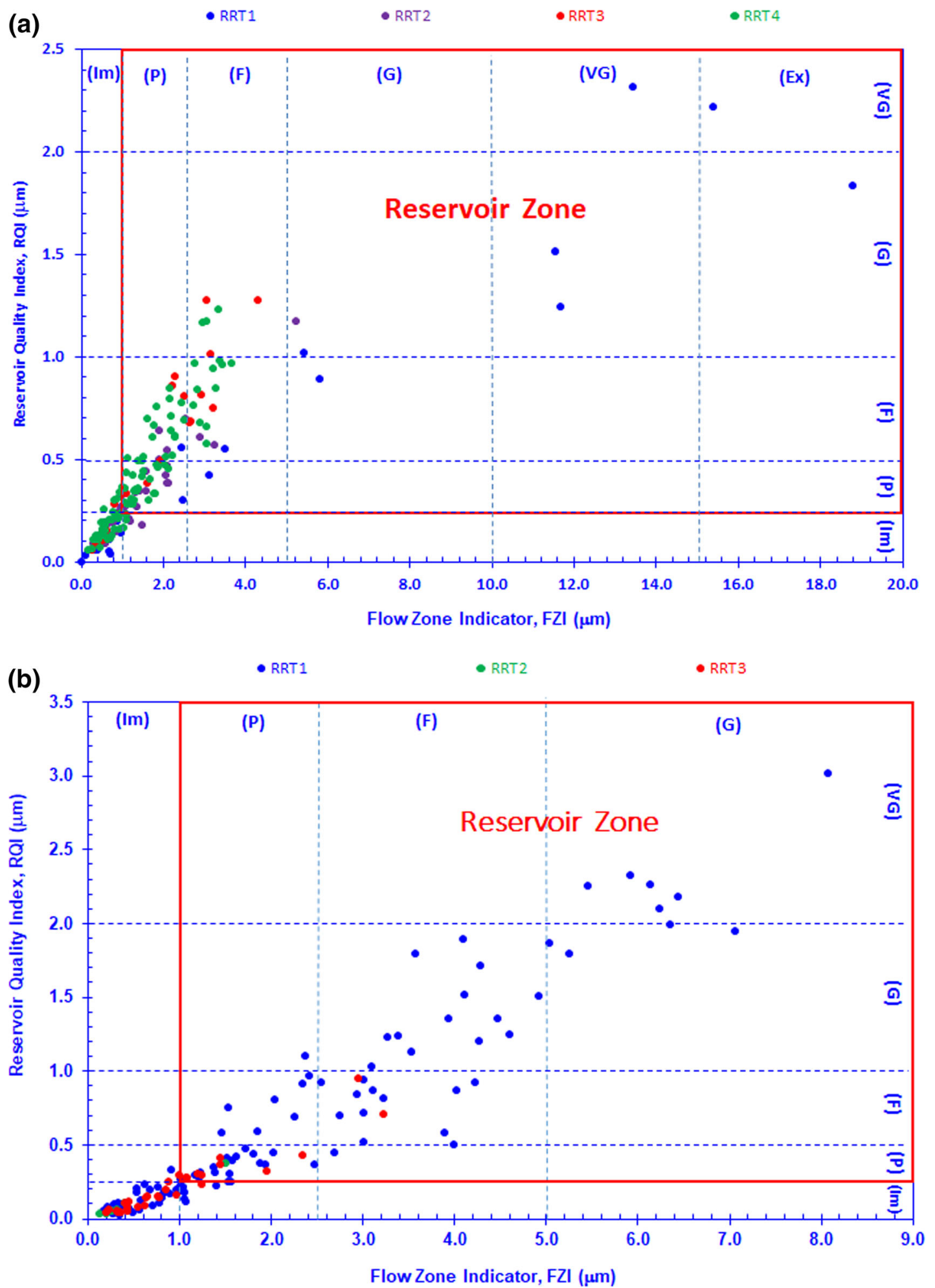

Figure 14. Plotting the Reservoir Quality Index 'RQI' versus the flow zone indicator 'FZI' for wells A1 and A2 (following ranks of Nabawy and Al-Azazi 2015; Nabawy and Barakat 2017). Note Im refers to impervious rank; P Poor rank, $F$ Fair rank, $G$ Good rank, $V G$ refers to a very good rank, and $E x$ refers to excellent rank. 


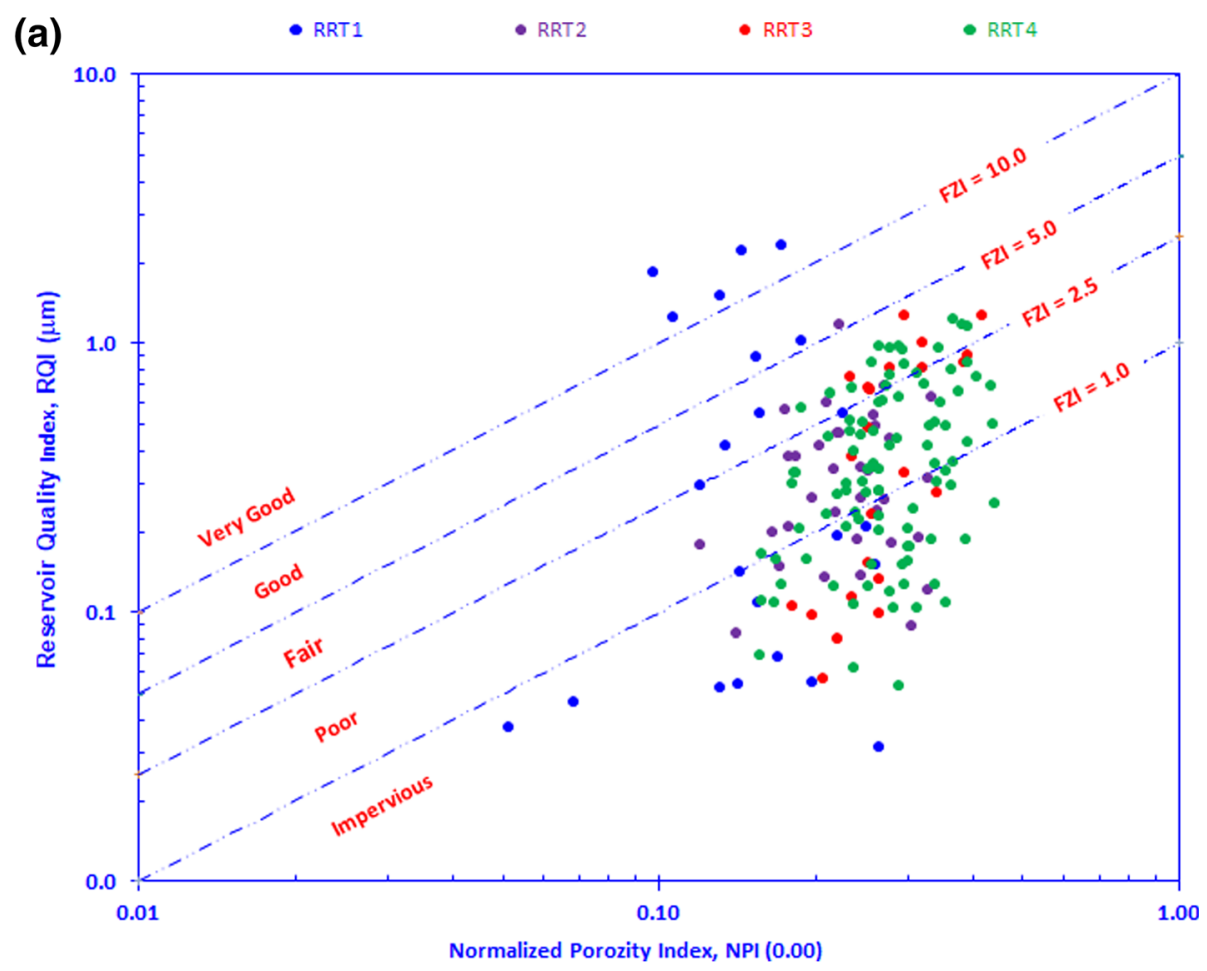

(b)

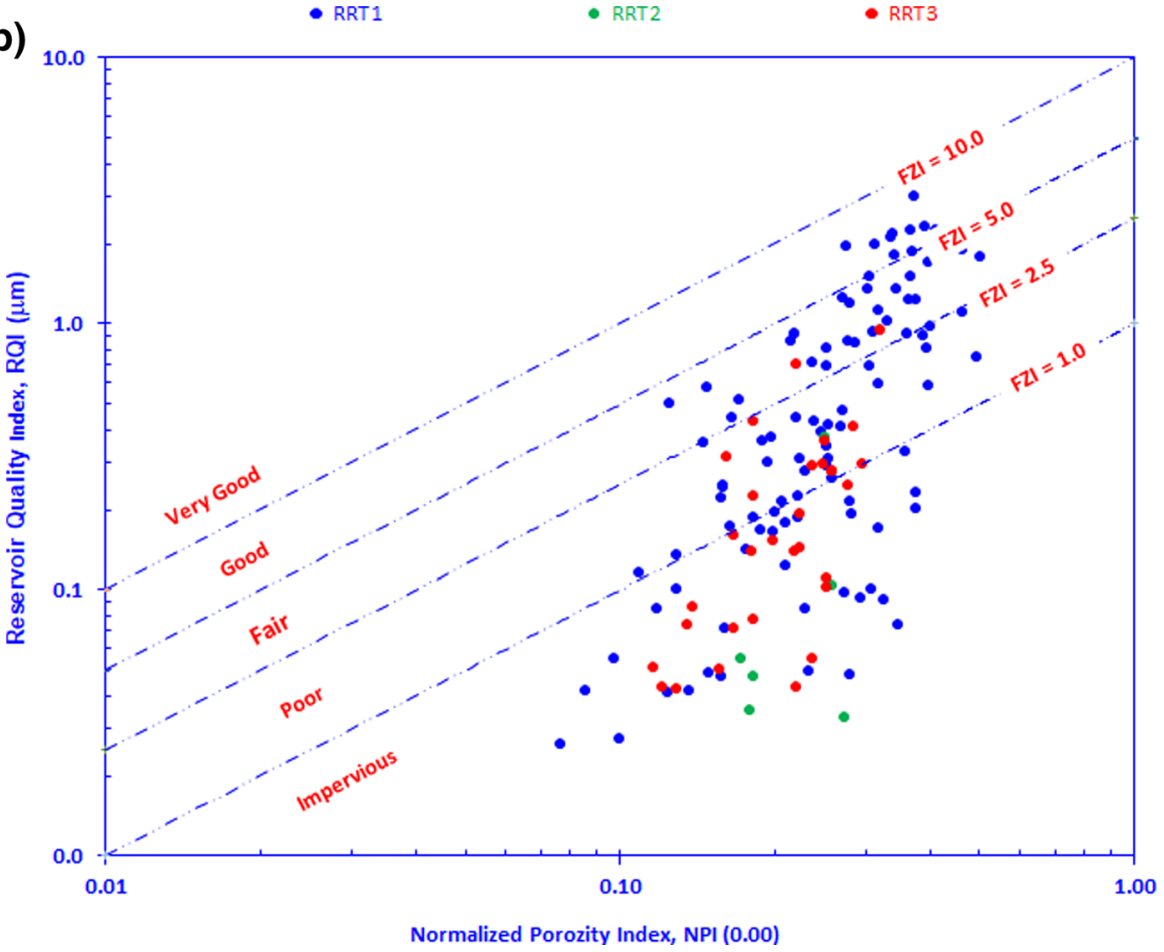

Figure 15. Plotting the Reservoir Quality Index 'RQI' vs. the normalized porosity index 'NPI' for: (a) A1 well, and (b) A2 well. 


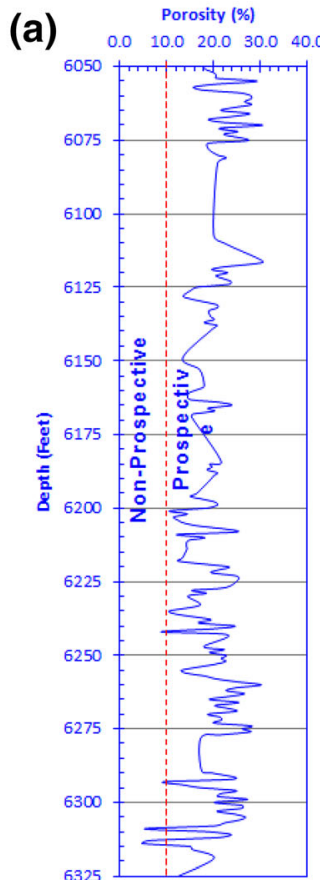

(b)
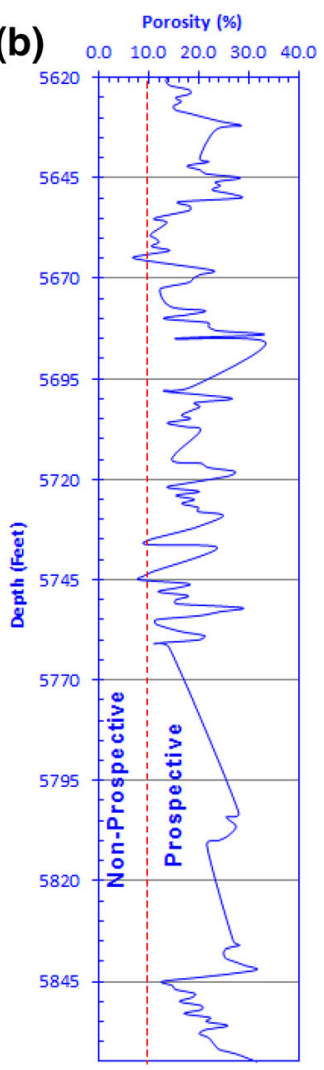

Permeability (md)

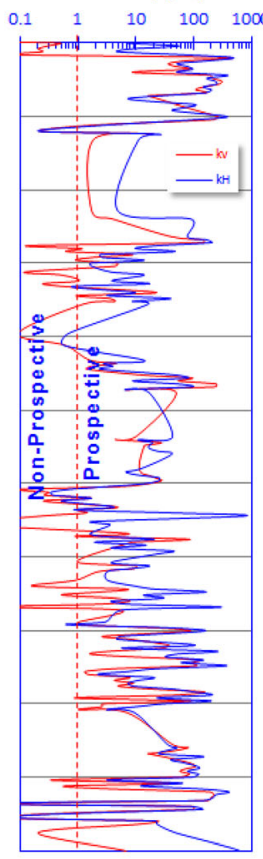

Permeability (md)

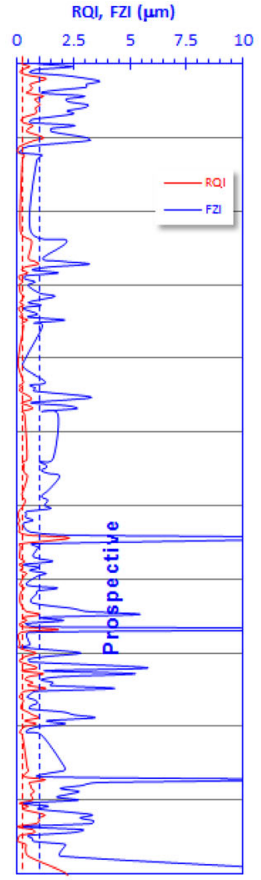

RQI, FZI ( $\mu \mathrm{m})$

\begin{tabular}{lllllll}
\multicolumn{1}{c}{$\operatorname{RPI}(0.00)$} \\
10 & 0.0 & 1.0 & 2.0 & 3.0 & 4.0 & 5.0
\end{tabular}
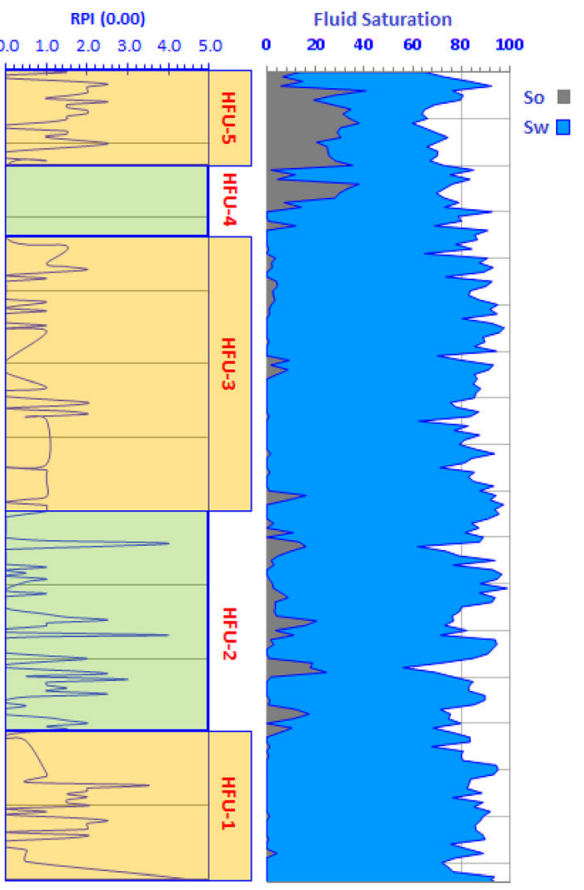

RPI (0.00)

Fluid Saturation

$\begin{array}{lllllll}10 & 0.0 & 1.0 & 2.0 & 3.0 & 4.0 & 5.0\end{array}$

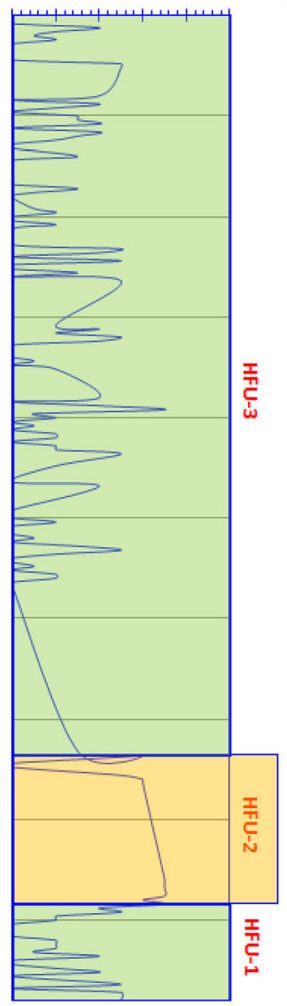

$\begin{array}{lllll}20 & 40 & 60 & 80 & 100\end{array}$
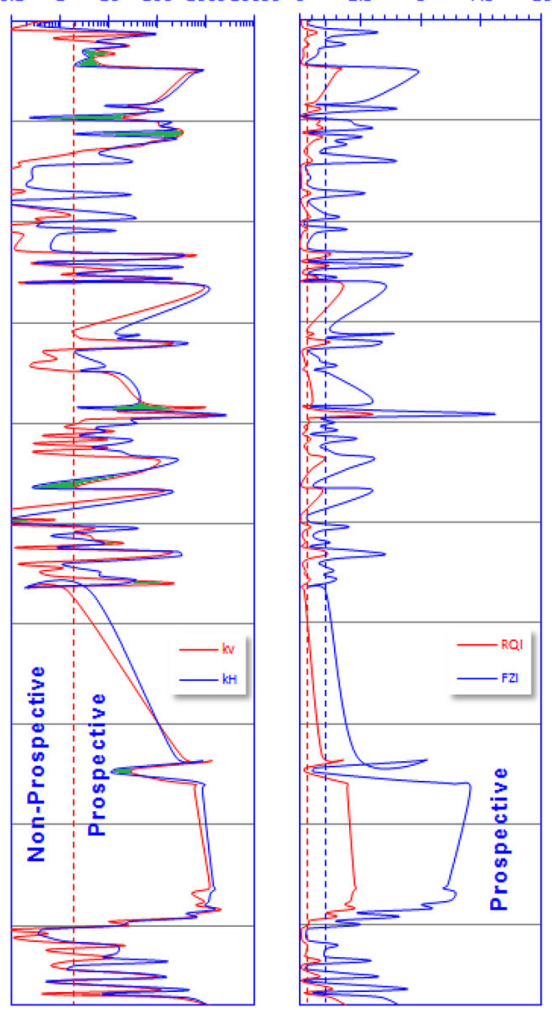

So

Sw $\square$

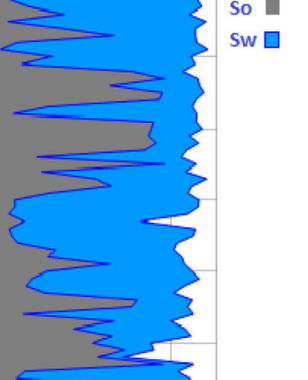

Figure 16. Vertical matching for the routine core analyses data, the reservoir quality parameters for wells A1 and A2. Cutoff values are taken as $\varnothing_{\mathrm{He}}=10 \%, k=1 \mathrm{md}, \mathrm{RQI}=0.25 \mu \mathrm{m}$, and FZI $=1.0 \mu \mathrm{m}$. Fractured zones are shown in green color and indicated from the cross over between the vertical and horizontal permeability. In the RPI track, the light green zones refer to non-conductive HFUs, whereas the orange color refers to conductive HFUs. 


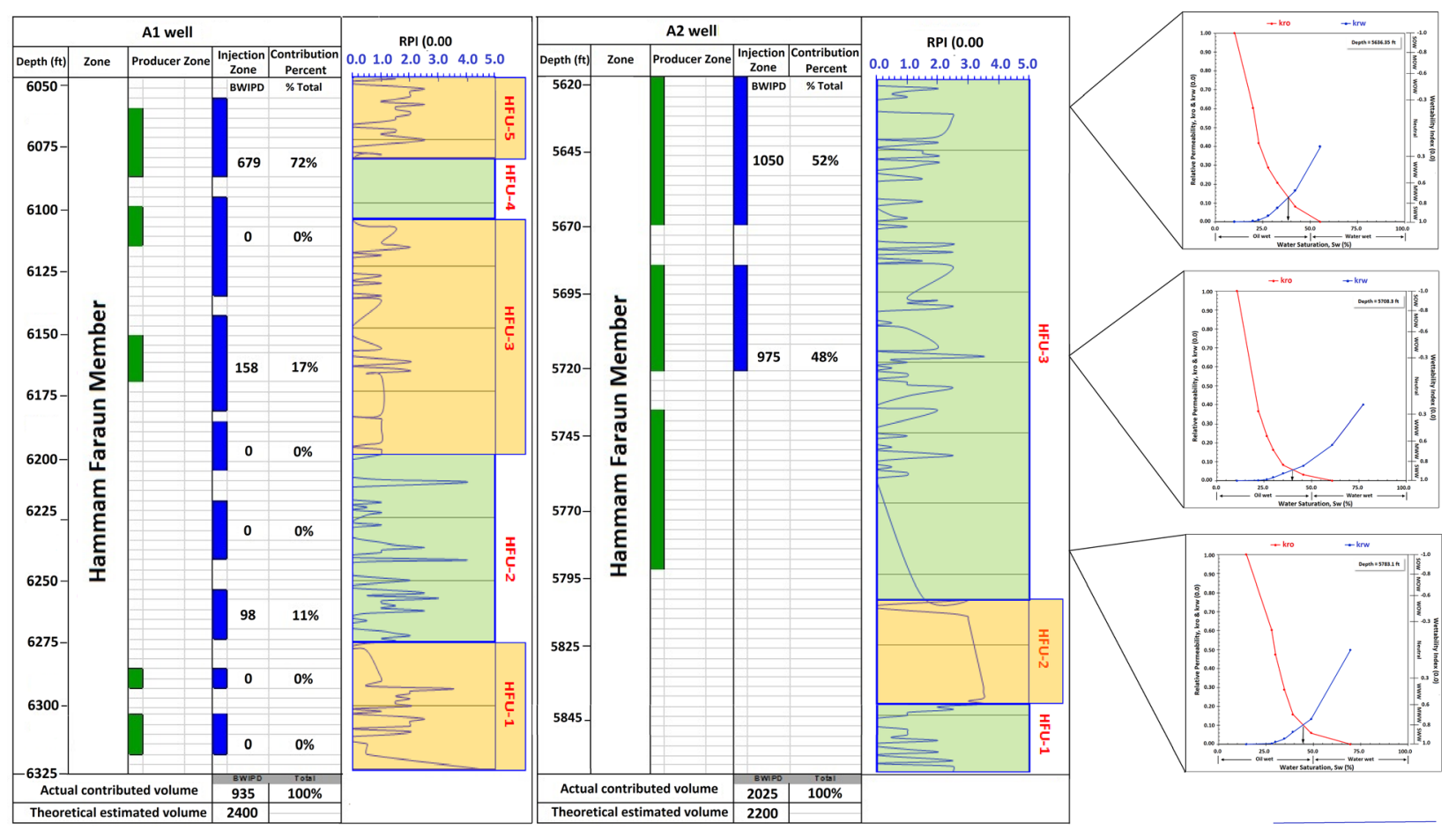

Figure 17. Injection sketch for wells $\mathrm{A} 1$ and $\mathrm{A} 2$. Relative permeability values $\left(k_{\mathrm{ro}} \& k_{\mathrm{rw}}\right.$, for relative permeabilities for oil and water, respectively) are estimated using the left axis, whereas the right axis is for measuring wettability based on the wettability index and classification of Nabawy et al. (2018b). Note: BWIPD is the barrels of water injected per day, green color intervals represent the producing intervals, and blue color intervals represent injector intervals. In the RPI track, the light green zones refer to non-conductive HFUs, whereas the orange color refers to conductive HFUs. SOW, MOW, and WOW refer to strongly, moderately and weakly oil-wet, respectively; whereas SWW, MWW, and WWW refer to strongly, moderately and weakly water-wet, respectively.

md permeability, reservoir pressure $33.78 \mathrm{MPa}(\mathrm{de}-$ pleted later to $16.55 \mathrm{MPa}), 67.056 \mathrm{~m}$ total perforated thickness, and $67.78^{\circ} \mathrm{C}$ reservoir temperature. The A1 well produced medium oil of $27^{\circ}$ API gravity (Table 1).

\section{Production and Injection History}

Limited oil production started from the Hammam Faraun reservoir in both the A1 and A2 wells, and then high water cut value has been recorded (up to $95 \%$ ); therefore, these wells were turned to water injection wells in the southern parts of the El Morgan field.

The estimated injection rate for the two wells commenced at 1500 BWIPD of water. The efficiency of water injection through the A2 well was much higher than in the A1 well, which indicated low-efficiency performance in the latter. The estimated theoretical volume of injected water through A1 well was 2400 BWIPD, while the actual contributed water was 935 BWIPD according to the production logging spinner surveys (PLSS) and production logging tools (PLT). Therefore, analyzing and matching the contributed water volume in the A1 well indicated that most of the injected water went through the upper part of the reservoir (72\%) with two streaks in the middle $(17 \%)$ and lower parts (11\%, Fig. 17).

Correlating the water injection profile in the A1 well and the vertical profile of the routine core data supports the presence of very good reservoir quality in top parts of Hammam Faraun (HFU-4, HFU-5) with some limited zones in the middle (HFU-3) and basal (HFU-2) parts (Fig. 16a). However, the contributed volume of injection water through the analog A2 well indicated that most of the injected water went through the different middle and upper intervals with similar contribution volumes (Fig. 17). Comparing the water injection profile in A2 well with the vertical matching for the routine core analysis supports the presence of very good reservoir 
quality belong to HFU-1 in the two perforated parts of Hammam Faraun (Fig. 16b).

\section{Reasons for Inefficiency of Waterflooding in A1 Well}

Globally, water injection efficiency decline was observed in many oil fields as mentioned by many authors (Shutong and Sharma 1997; Sharma et al. 2000; Bedrikovetsky et al. 2005; Nunes et al. 2010; Dambani et al. 2014). They tied the injection efficiency decline to the quality of the injected water. For the present study, integrating the geological and reservoir engineering data indicated that the Hammam Faraun sequence in the El Morgan A1 well had low reservoir quality and high heterogeneity than in the analog A2 well. Therefore, the efficiency decline of the waterflooding through A1 well was generally attributed to the heterogeneity of the reservoir sequence. Although the Hammam Faraun reservoir was generally heterogeneous through the investigated and analog wells, the efficiency of water injection in A1 well was mostly (72\%) assigned to the most top parts of the sequence as the main contributor in the injection job (Fig. 17), i.e., forcing the oil to move down causing disturbance inside the reservoir. The other reservoir parts indicate less contribution (28\%) to the injection job due to their poor reservoir quality. In other words, the oil was not swept and enforced properly to migrate horizontally from the injection to the producing well.

The low-quality HFUs and the heterogeneity of the Hammam Faraun sequence in the A1 well reduced the efficiency of the water injection project to $39 \%$ (actual/estimated injection volume was 935/ 2400 BWIPD). In contrast, high-quality HFUs were present in middle and upper parts in the analog A2 well, and so the injected water volume was contributed through the different perforated intervals with very high injection efficiency (actual/estimated injected volume was 2025/2200 BWIPD, 92\%). The contribution of water injection was nearly equally distributed along with the well profile (Fig. 17). For the present study, we do not have much data about the perforation strategy of the studied wells at the time of perforation and injection, which was a long time ago. However, assessing the core data and HFU analysis in the two wells may indicate that the oil production, perforation, and water injection were not perfect. In terms of oil production perforation strategy, and based on the HFU analysis for the A1 and A2 wells (Figs. 16a, 17), it can be seen that the HFU2 had the best reservoir quality. However, no perforation was seen in that interval and it was completely neglected. In terms of water injection perforation strategy after converting the two wells to injection wells, and based on the HFU analysis for A1 well (Figs. 16a, 17), it can be seen that the injection process had been performed along eight zones that cover almost the whole intervals representing five HFU zones without any consideration for the different rock types. In addition, based on the HFU analysis for A2 well (Figs. 16b, 17), it can be noticed that the injection intervals had been performed in HFU-3. According to the integration of previous data, the injection perforation strategy had not been built on an adequate understanding of the HFUs and RRTs analysis discussed in this study. The afore-mentioned reason is additional reason for the successful/unsuccessful water injection implementations in these two wells.

The mobility ratio $(k / \mu)$ is additional point that should be taken into consideration while analyzing the data. High mobility ratio has played a significant role in the waterflooding process resulting in inefficient fluid displacements in some fields globally (Willhite 1986; Kumar et al. 2008; Kalam et al. 2020). If the mobility ratio in waterflooding process is less than 1, this means a stable case, while a value greater than 1 may lead to viscous fingering and inefficient displacement. It was found that the mobility ratios in the studied field ranged between 0.85 and 0.91 , i.e., they were considered stable and the probability for developing viscous fingering was very low.

The relative permeability values for water and oil in both wells ( $k_{\mathrm{rw}} \& k_{\mathrm{ro}}$, respectively) were represented at different levels and superimposed with two different techniques for measuring wettability index. First, the common technique of intersection point between the oil and water relative permeability curves and its corresponding water saturation value (Fig. 17). Second, wettability index for water based on relative permeability value $\left(k_{\mathrm{rw}}\right)$ and its classification following the classification of Nabawy et al. (2018b) (Fig. 17). It can be calculated as (Nabawy et al. 2018b):

$$
\text { Wettability index }=2 \times\left(0.5-k_{\mathrm{rw}-\max }\right) \text {. }
$$

Based on these two classifications, the relative permeability plots of the studied reservoir at different depths indicated that the injection zones and HFUs of the studied reservoir were neutral to oil- 
wet (Fig. 17). This should control the efficiency of the injection process, where efficiency of waterflooding in hydrophobic reservoirs is less efficient than that in hydrophilic reservoirs. This can be overcome by increasing the salinity of the injected water, which may change wettability of the injected HFUs from oil-wet to water-wet.

Therefore, it is clearly indicated that rock typing and inadequate injection perforation strategy are key control parameters in waterflooding efficiency. Some alternatives that can be considered in the studied heterogeneous zones of the A1 well include alternatives enhancement techniques such as the remedial application of $\mathrm{O} / \mathrm{W}$ emulsions (Sadati and Sahraei 2019), smart waterflooding including low salinity flooding, combined nano-fluid low salinity flooding, and injecting a brine containing bicarbonates (Yuan et al. 2016; Wood and Yuan 2018; Wei et al. 2018). Besides, other chemical treatments and re-perforation of some selected zones can be taken into consideration. In addition, waterflooding performance can be predicted by newly developed techniques using empirical equations (Kalam 2016; Kalam et al. 2020).

\section{CONCLUSIONS}

The Hammam Faraun reservoir can be divided into four reservoir rock types in the A1 well (dolomitic limestones, calcareous to ferruginous arkose, argillaceous arkose, and calcareous arkose), whereas in the analog A2 well there are three reservoir units (ferruginous arkose, dolomitic arkose, and argillaceous arkose). To model the porosity, permeability, and reservoir quality parameters of the Hammam Faraun reservoir, a set of highly reliable $X-Y$ plots were introduced, including $\varnothing-\sigma_{\mathrm{b}}, k-\varnothing, k_{\mathrm{V}}-$ $k_{\mathrm{H}}$, RQI- $k$, RQI-FZI, and RQI-NPI. These reservoir plots indicated that the studied Hammam Faraun reservoir has poor to good reservoir quality. Based on the Dykstra-Parsons technique, the reservoir was heterogeneous $(V>0.75)$.

Five HFUs were identified in the A1 well, with the best quality near the top. Three HFUs were present in the analog A2 well, with high-quality zones distributed at different depths through the sequence. Integrating the documented petrographical and petrophysical results with the engineering data and the injection profile of the A1 well, it was recognized that waterflooding was most efficient only at the top of the sequence in the A1 well (72\%), and so the injection process was inefficient in the other reservoir zones. It is clearly indicated that rock typing and inadequate injection perforation strategy are key control parameters in waterflooding efficiency. Moreover, the injection perforation strategy did not build on adequate understanding of the HFU and rock type analysis, as discussed in this study. Therefore, we can conclude that rock typing is an important factor in the success and efficiency of waterflooding projects. In addition, it is important to understand reservoir HFUs adequately based on core data to optimize the efficiency of the waterflood. In the El Morgan Field, the low-efficiency injector A1 well should be replaced by another injector that has the same rock types as the analog the A2 well and/or other alternatives of enhancement techniques can be used such as the remedial application of $\mathrm{O} / \mathrm{W}$ emulsions, smart waterflooding including (low salinity flooding, combined nano-fluid low salinity flooding and injection of the brine containing bicarbonates), other chemical treatments and re-perforation of selected zones can be evaluated according to further studies. For further development of the El Morgan Field, especially and other relevant oil fields elsewhere, it is important to consider more accurate reservoir characteristics of heterogeneous reservoirs based on core data to create a more efficient waterflood.

\section{ACKNOWLEDGMENTS}

Great thanks to the anonymous reviewers and Prof Dr. John Carranza, Editor-in-Chief of Natural Resources Research, for their comments and suggestions, which greatly benefited and reconstructed the manuscript. The authors are grateful to the Gulf of Suez Petroleum Company (GUPCO) and the Egyptian General Petroleum Corporation (EGPC) for providing the required data and permissions to carry out the current research. Interpretation documented in this manuscript solely reflects the authors and does not necessarily represent his respective organizations. Ahmed E. Radwan expresses his deepest thanks to the Narodowa Agencja Wymiany Akademickiej (NAWA) under Project PPN/ULM/ 2019/1/00305/U/00001 for supporting during this research time as well as deep thanks to Prof. Alfred Uchman for his continuous support during the research period. 


\section{OPEN ACCESS}

This article is licensed under a Creative Commons Attribution 4.0 International License, which permits use, sharing, adaptation, distribution and reproduction in any medium or format, as long as you give appropriate credit to the original author(s) and the source, provide a link to the Creative Commons licence, and indicate if changes were made. The images or other third party material in this article are included in the article's Creative Commons licence, unless indicated otherwise in a credit line to the material. If material is not included in the article's Creative Commons licence and your intended use is not permitted by statutory regulation or exceeds the permitted use, you will need to obtain permission directly from the copyright holder. To view a copy of this licence, visit http://creativecom mons.org/licenses/by/4.0/.

\section{REFERENCES}

Abdelghany, W. K., Radwan, A. E., Elkhawaga, M. A., Wood, D. A., Sen, S., \& Kassem, A. A. (2020). Geomechanical modeling using the depth-of-damage approach to achieve successful underbalanced drilling in the Gulf of Suez Rift Basin. Journal of Petroleum Science and Engineering. https://doi.or $\mathrm{g} / 10.1016 / \mathrm{j}$.petrol.2020.108311.

Abudeif, A. M., Attia, M. M., Al-Khashab, H. M., \& Radwan, A. E. (2018). Hydrocarbon type detection using the synthetic logs: A case study, Baba member, Gulf of Suez, Egypt. Journal of African Earth Sciences, 144, 176-182.

Abudeif, A., Attia, M. M., \& Radwan, A. E. (2016a). New simulation technique to estimate the hydrocarbon type for the two untested members of Belayim Formation in the absence of pressure data, Badri Field, Gulf of Suez, Egypt. Arabian Journal of Geosciences, 9(3), 1-21.

Abudeif, A., Attia, M. M., \& Radwan, A. E. (2016b). Petrophysical and petrographic evaluation of Sidri Member of Belayim Formation, Badri field, Gulf of Suez, Egypt. Journal of African Earth Sciences, 115, 108-120.

Ahmed, T. (2019). Principles of waterflooding. In Ahmed, T. (Ed.) Reservoir engineering handbook (pp. 901-1107). http s://doi.org/10.1016/B978-0-12-813649-2.00014-1.

Al-Attar, H. H., Mahmoud, M. Y., Zekri, A. Y., Almehaideb, R., \& Ghannam, M. (2013). Low-salinity flooding in a selected carbonate reservoir: experimental approach. Journal of Petroleum Exploration and Production Technology, 3(2), 139149.

Ali, Kh A, Abd Elrazik, E. E. D., Azam, S Sh, \& Saleh, A. H. (2016). Integrated petrophysical and lithofacies studies of lower-middle Miocene reservoirs in Belayim marine oil field, Gulf of Suez, Egypt. Journal of African Earth Sciences, 117, 331-344.

Alsharhan, A. S. (2003). Petroleum geology and potential hydrocarbon plays in the Gulf of Suez rift basin, Egypt. AAPG bulletin, 87(1), 143-180.

Amaefule, J. O., Altunbay, M., Tiab, D., Kersey, D. G., \& Keelan, D. K. (1993). Enhanced reservoir description: Using core and $\log$ data to identify hydraulic (flow) units and predict permeability in uncored intervals/wells. SPE Annual Technical Conference and Exhibition. https://doi.org/10.2118/26436-ms.

Anovitz, L. M., \& Cole, D. R. (2015). Characterization and analysis of porosity and pore structures. Reviews in Mineralogy and Geochemistry, 80(1), 61-164.

Anovitz, L. M., Cole, D. R., Rother, G., Allard, L. F., Jackson, A. J., \& Littrell, K. C. (2013). Diagenetic changes in macro-to nano-scale porosity in the St. Peter Sandstone: An (ultra) small angle neutron scattering and backscattered electron imaging analysis. Geochimica et Cosmochimica Acta, 102, 280-305.

Attia, M., Abudeif, A., \& Radwan, A. (2015). Petrophysical analysis and hydrocarbon potentialities of the untested Middle Miocene Sidri and Baba sandstone of Belayim Formation, Badri field, Gulf of Suez, Egypt. Journal of African Earth Sciences, 109, 120-130.

Bedrikovetsky, P. G., Da Silva, M. J., Fonseca, R. D., Da Silva, M. F., Siqueira, A. G., de Souza, A. L., et al. (2005). Well-history-based prediction of injectivity decline during seawater flooding. SPE European Formation Damage Conference. $\mathrm{h}$ ttps://doi.org/10.2118/93886-ms.

Bennion, D. B., Thomas, F. B., \& Bietz, R. F. (1996). Formation damage and horizontal wells-A productivity killer? International Conference on Horizontal Well Technology. https://d oi.org/10.2118/37138-ms.

Bennion, D. B., Thomas, F. B., Bietz, R. F., \& Bennion, D. W. (1998). Underbalanced drilling: Praises and perils. SPE Drilling \& Completion, 13(4), 214-222.

Bentley, B. B., \& Biller, E. J. (1990). Exploitation study and impact on the Kareem Formation, South EI Morgan Field, Gulf of Suez, Egypt. In Offshore technology conference. https://doi. org/10.4043/6270-ms.

Bosworth, W., \& McClay, W. (2001). Structural and stratigraphic evolution of the Gulf of Suez rift, Egypt: A synthesis. Mémoires du Muséum national d'histoire naturelle, 186, 567606.

Colombo, D., \& McNeice, G. (2017). Geophysical monitoring of waterflooding in Saudi Arabia: Methods and perspectives. SEG Technical Program Expanded Abstracts. https://doi.org/ 10.1190/segam2017-17583120.1.

Craig, F. F. (1971). The reservoir engineering aspects of waterflooding (Vol. 3, pp. 12-44). New York: HL Doherty Memorial Fund of AIME.

Dambani, S. L., Blunt, M. J., Tendo, F., Lawal, K. A. (2014). Analysis of injectivity decline in some offshore water injectors. In SPE Nigeria annual international conference and exhibition, 5-7 August, Lagos, Nigeria SPE-172469-MS.

Desbois, G., Urai, J. L., Kukla, P. A., Konstanty, J., \& Baerle, C. (2011). High-resolution 3D fabric and porosity model in a tight gas sandstone reservoir: A new approach to investigate microstructures from mm-to nm-scale combining argon beam cross-sectioning and SEM imaging. Journal of Petroleum Science and Engineering, 78(2), 243-257.

Dykstra, H., \& Parsons, R.L. (1950). The prediction of oil recovery by water flood. In American petroleum institute, secondary recovery of oil in the United States (2nd ed., pp. 160-174). Dallas: API.

Ebanks, W. J. Jr. (1987). Flow unit concept-integrated approach to reservoir description for engineering projects. $A A P G$ Bulletin, 71:5, Report No. CONF-870606.

EGPC, Egyptian General Petroleum Corporation. (1996). Gulf of Suez oil fields (a comprehensive overview). Cairo.

El Sharawy, M. S., \& Nabawy, B. S. (2016a). Determination of electrofacies using wireline logs based on multivariate statistical analysis for the Kareem Formation, Gulf of Suez, Egypt. Environmental Earth Sciences 75(21), Article 1394.

El Sharawy, M. S., \& Nabawy, B. S. (2016b). Geological and petrophysical characterization of the lower Senonian Matulla 
Formation in Southern and Central Gulf of Suez, Egypt. Arabian Journal for Science and Engineering, 41(1), 281-300. El Sharawy, M. S., \& Nabawy, B. S. (2018). Determining the porosity exponent $\mathrm{m}$ and lithology factor a for sandstones and their control by overburden pressure: A case study from the Gulf of Suez, Egypt. AAPG Bulletin, 102(9), 1893-1910.

El Sharawy, M. S., \& Nabawy, B. S. (2019). Integration of electrofacies and hydraulic flow units to delineate reservoir quality in uncored reservoirs: A case study, Nubia sandstone reservoir, Gulf of Suez, Egypt. Natural Resources Research, 28(4), 1587-1608.

El-Gezeery, M. V., \& Marzouk, I. M. (1974). Miocene rock stratigraphy of Egypt. Journal of Egyptian Geological Society, 18(1), 1-59.

Feng, X., Wen, X. H., Li, B., Liu, M., Zhou, D. G., Ye, Q. C., et al. (2009). Water-injection optimization for a complex fluvial heavy-oil reservoir by integrating geological, seismic, and production data. SPE Reservoir Evaluation Engineering, 12, 6. https://doi.org/10.2118/110492-PA.

Gawad, W. A., Gaafar, I., \& Sabour, A. A. (1986). Miocene stratigraphic nomenclature in the Gulf of Suez region. In: Egyptian general petroleum corporation, 8th exploration conference (pp. 1-20).

Gulick, K. E., \& McCain, Jr. W. D. (1998). Waterflooding heterogeneous reservoirs: An overview of industry experiences and practices. In International petroleum conference and exhibition of Mexico. Society of Petroleum Engineers.

Hermina, M., Klitzsch, E., \& List, F. K. (1989). Stratigraphic lexicon and explanatory notes to the geological map of Egypt. Cairo: Conoco Coral and Egyptian General Petroleum Corporation.

Hughes, S. C., Ahmed, H., \& Raheem, T. A. (1997). Exploiting the mature South El Morgan Kareem reservoir for yet more oil-A case study in multidiscipline reservoir management. In Proceeding SPE 10th middle east oil show, Bahrain, SPE 37783 (pp. 243-253).

Jackson, Ch A L, Gawthorpe, R. L., Leppard, Ch., \& Sharp, I. (2006). Rift-initiation development of normal fault blocks: Insights from the Hammam Faraun fault block, Suez Rift, Egypt. Journal of the Geological Society, 163(1), 165-183.

Kalam, S. (2016). An empirical correlation for water flooding performance in a layered reservoir, Master thesis. Saudi Arabia: King Fahd University of Petroleum and Minerals.

Kalam, S., Abu-Khamsin, S. A., Al-Yousef, H. Y., et al. (2020). A novel empirical correlation for waterflooding performance prediction in stratified reservoirs using artificial intelligence. Neural Computing \& Applications. https://doi.org/10.1007/s0 0521-020-05158-1.

Khalil, B., \& Meshrif, W. M. (1988). Hydrocarbon occurrences and structural style of the southern Suez Rift Basin, Egypt. In: 9th Petroleum exploration and production conference, Cairo (pp. 86-109).

Kok, M. V. (2011). The application of water-flood technology for different oil fields. Energy Sources, Part A: Recovery, Utilization, and Environmental Effects, 33(5), 377-382.

Kassem, A. A., Hussein, W. S., Radwan, A. E., Anani, N., Abioui, M., Jain, S., \& Shehata, A. A. (2021). Petrographic and diagenetic study of siliciclastic jurassic sediments from the Northeastern margin of Africa: Implication for reservoir quality. Journal of Petroleum Science and Engineering. http s://doi.org/10.1016/j.petrol.2020.108340.

Kumar, M., Hoang, V. T., Satik, C., \& Rojas, D. H. (2008). Highmobility-ratio waterflood performance prediction: Challenges and new insights. SPE Reservoir Evaluation \& Engineering, 11(01), 186-196.

Moghadasi, J., Jamialahmadi, M., Müller-Steinhagen, H., Sharif, A., Izadpanah, M. R., Motaei, E., et al. (2002). Formation damage in Iranian oil fields. International Symposium and
Exhibition on Formation Damage Control. https://doi.org/10. 2118/73781-ms.

Morrow, N., \& Buckley, J. (2011). Improved oil recovery by lowsalinity waterflooding. Journal of Petroleum Technology, 63(05), 106-112.

Nabawy, B. S. (2018). Impacts of the fossil anisotropy on the electric and permeability anisotropy of the highly fossiliferous limestone: A case study. Marine Geophysical Research, 39(4), 537-550.

Nabawy, B. S., \& Al-Azazi, N. A. (2015). Reservoir zonation and discrimination using the routine core analyses data: The upper Jurassic Sab'atayn sandstones as a case study, Sab'atayn basin, Yemen. Arabian Journal of Geosciences, 8(8), 55115530 .

Nabawy, B. S., \& Barakat, M Kh. (2017). Formation evaluation using conventional and special core analyses: Belayim Formation as a case study, Gulf of Suez, Egypt. Arabian Journal of Geosciences, 10(2), 25.

Nabawy, B. S., Basal, A. M. K., Sarhan, M. A., \& Safa, M. G. (2018a). Reservoir zonation, rock typing and compartmentalization of the Tortonian-Serravallian sequence, Temsah Gas Field, offshore Nile Delta, Egypt. Marine and Petroleum Geology, 92, 609-631.

Nabawy, B. S., \& David, C. (2016). X-Ray CT scanning imaging for the Nubia sandstone as a tool for characterizing its capillary properties. Geosciences Journal, 20(5), 691-704.

Nabawy, B. S., \& El Sharawy, M. S. (2015). Hydrocarbon potential, structural setting and depositional environments of Hammam Faraun Member of the Belayim Formation, Southern Gulf of Suez, Egypt. Journal of African Earth Sciences, 112, 93-110.

Nabawy, B. S., \& Géraud, Y. (2016). Impacts of pore- and petrofabrics, mineral composition and diagenetic history on the bulk thermal conductivity of sandstones. Journal of African Earth Sciences, 115, 48-62.

Nabawy, B. S., Rashed, M. A., Mansour, A. S., \& Afify, W. S. M. (2018b). Petrophysical and microfacies analysis as a tool for reservoir rock typing and modeling: Rudeis Formation, offshore October Oil Field, Sinai. Marine and Petroleum Geology, 97, 260-276.

Nabawy, B. S., Sediek, K. N., \& Nafee, S. A. (2015). Pore fabric assignment using electrical conductivity of some AlbianCenomanian sequences in north Eastern Desert, Egypt. Arabian Journal of Geosciences, 8, 5601-5615. https://doi.org/ 10.1007/s12517-014-1631-4.

Nasralla, R. A., Alotaibi, M. B., \& Nasr-El-Din, H. A. (2011). Efficiency of oil recovery by low salinity water flooding in sandstone reservoirs. SPE Western North American Region Meeting. https://doi.org/10.2118/144602-ms.

Nunes, M., Bedrikovetsky, P., Newbery, B., Paiva, R., Furtado, C., \& De Souza, A. L. (2010). Theoretical definition of formation damage zone with applications to well stimulation. Journal of Energy Resources Technology, 132(3), 033101.

Radwan, A. E. (2014). Petrophysical evaluation for Sidri and Baba members within Belayim Formation in the region of Badri field, Gulf of Suez, Egypt. M.Sc. Thesis https://doi.org/ 10.13140/rg.2.2.22772.09601

Radwan, A. E. (2018). New petrophysical approach and study of the pore pressure and formation damage in Badri, Morgan and Sidki fields, Gulf of Suez Region Egypt: PhD Thesis. h ttps://doi.org/10.13140/rg.2.2.26651.82727.

Radwan, A. E. (2020a). Wellbore stability analysis and pore pressure study in Badri field using limited data, Gulf of Suez, Egypt. In AAPG/datapages search and discovery Article \#20476 (2020). https://doi.org/10.1306/20476radwan2020.

Radwan, A. E. (2020b). Hydrocarbon type estimation using the synthetic logs: A case study in Baba Member, Gulf of Suez, Egypt. In AAPG/datapages search and discovery Article \#20475 (2020). https://doi.org/10.1306/20475radwan2020. 
Radwan, A. E. (2020c). Effect of clay minerals in oil and gas formation damage problems and production decline: A case study, Gulf of Suez, Egypt. In AAPG/datapages search and discovery Article \#20477 (2020). https://doi.org/10.1306/2047 7 radwan 2020.

Radwan, A. E. (2020d). Modeling the depositional environment of the sandstone reservoir in the Middle Miocene Sidri Member, Badri Field, Gulf of Suez Basin, Egypt: Integration of gamma-ray log patterns and petrographic characteristics of lithology. Natural Resources Research https://doi.org/10.1007/ s11053-020-09757-6.

Radwan, A. E., Abudeif, A. M., \& Attia, M. M. (2020a). Investigative petrophysical fingerprint technique using conventional and synthetic logs in siliciclastic reservoirs: A case study, Gulf of Suez basin, Egypt. Journal of African Earth Sciences, 167, 103868.

Radwan, A. E., Abudeif, A. M., Attia, M. M., Elkhawaga, M. A., Abdelghany, W. K., \& Kasem, A. A. (2020b). Geopressure evaluation using integrated basin modelling, well-logging and reservoir data analysis in the northern part of the Badri oil field, Gulf of Suez, Egypt. Journal of African Earth Sciences, 162, 103743

Radwan, A. E., Abudeif, A. M., Attia, M. M., \& Mahmoud, M. A. (2019a). Development of formation damage diagnosis workflow, application on Hammam Faraun reservoir: A case study, Gulf of Suez, Egypt. Journal of African Earth Sciences, 153, 42-53. https://doi.org/10.1016/j.jafrearsci.2019.02.012.

Radwan, A. E., Abudeif, A., Attia, M., \& Mahmoud, M. (2019c). Formation damage diagnosis, application on Hammam Faraun reservoir: A case study, gulf of Suez, Egypt. In Offshore mediterranean conference. https://doi.org/10.13140/rg.2.2.223 52.66569

Radwan, A.E., Abudeif, A., Attia, M., \& Mahmoud, M. (2019d). Development of formation damage diagnosis workflow, application on Hammam Faraun reservoir: a case study, Gulf of Suez, Egypt. In Offshore mediterranean conference. ISBN9788894043679-2019.

Radwan, A. E., Abudeif, A. M., Attia, M. M., \& Mohammed, M. A. (2019b). Pore and fracture pressure modeling using direct and indirect methods in Badri Field, Gulf of Suez. Egypt. Journal of African Earth Sciences, 156, 133-143. https://doi. org/10.1016/j.jafrearsci.2019.04.015.

Radwan, A. E., Kassem, A. A., \& Kassem, A. (2020c). Radwany formation: A new formation name for the Early-Middle Eocene carbonate sediments of the offshore October oil field, Gulf of Suez: Contribution to the Eocene sediments in Egypt. Marine and Petroleum Geology, 116, 104304. https://doi.org/ 10.1016/j.marpetgeo.2020.104304.

Radwan, A., \& Sen, S. (2020). Stress path analysis for characterization of in situ stress state and effect of reservoir depletion on present-day stress magnitudes: Reservoir geomechanical modeling in the gulf of Suez Rift Basin, Egypt. Natural Resources Research. https://doi.org/10.1007/s11053-020-09731-2.

Radwan, A. E., Trippetta, F., Kassem, A. A., \& Kania, M. (2020d). Multi-scale characterization of unconventional tight carbonate reservoir: Insights from October oil filed, Gulf of Suez rift basin, Egypt. Journal of Petroleum Science and Engineering. https://doi.org/10.1016/j.petrol.2020.107968.
Rashed, A. (1990). The main fault trends in the Gulf of Suez and their role in oil entrapment. In 10th Petroleum exploration and production conference, Cairo (pp. 1-24).

Richardson, M., \& Arthur, M. A. (1988). The Gulf of Sueznorthern Red Sea Neogene rift: A quantitative basin analysis. Marine and Petroleum Geology, 5, 247-270.

Sadati, Y., \& Sahraei, E. (2019). An experimental investigation on enhancing water flooding performance using oil-in-water emulsions in an Iranian oil reservoir. Journal of Petroleum Exploration and Production Technology, 9(4), 2613-2624.

Salah, M. G., \& Alsharhan, A. S. (1997). The Miocene Kareem Formation in the southern Gulf of Suez, Egypt: A review of stratigraphy and petroleum geology. Journal of Petroleum Geology, 20(3), 327-346.

Scheihing, M. H., Thompson, R. D., \& Seifert, D. (2002). Multiscale reservoir description models for performance prediction in the Kuparuk River Field, North Slope of Alaska. In SPE Western Regional/AAPG Pacific Section Joint Meeting, Anchorage, 20-22 May. SPE-76753-MS.

Serra, O. (1984). Fundamentals of well-log interpretation-1. The acquisition of logging data. Developments in Petroleum Science. https://doi.org/10.1016/s0376-7361(08)x7023-2.

Sharma, M. M., Pang, Sh, Wennberg, K. E., \& Morgenthaler, L. N. (2000). Injectivity decline in water-injection wells: An offshore Gulf of Mexico case study. SPE Production \& Facilities, 15(01), 6-13.

Shiran, S. B., \& Skauge, A. (2013). Enhanced oil recovery (EOR) by combined low salinity water/polymer flooding. Energy \& Fuels, 27(3), 1223-1235.

Shutong, P., \& Sharma, M. M. (1997). A model for predicting injectivity decline in water-injection wells. SPE Formation Evaluation, 12(03), 194-201.

Tang, G. Q., \& Morrow, N. R. (1997). Salinity, temperature, oil composition, and oil recovery by waterflooding. SPE Reservoir Engineering, 12(04), 269-276.

Wei, P., Pu, W., Sun, L., Pu, Y., Wang, S., \& Fang, Z. (2018). Oil recovery enhancement in low permeable and severe heterogeneous oil reservoirs via gas and foam flooding. Journal of Petroleum Science and Engineering, 163, 340-348.

Willhite, G. P. (1986). Waterflooding. In Society of petroleum engineers, technology \& engineering.

Wood, D. A., \& Yuan, B. (2018). Low-salinity water flooding. Formation damage during improved oil recovery (pp. 21-67). In Yuan, B., \& Wood, D. A. (Ed.) Formation damage during improved oil recovery. https://doi.org/10.1016/b978-0-12-8137 82-6.00002-6.

Yasari, E., Pishvaie, M. R., Khorasheh, F., Salahshoor, K., \& Kharrat, R. (2013). Application of multi-criterion robust optimization in water-flooding of oil reservoir. Journal of Petroleum Science and Engineering, 109, 1-11.

Yuan, B., Moghanloo, R. G., \& Zheng, D. (2016). Enhanced oil recovery by combined nanofluid and low salinity water flooding in multi-layer heterogeneous reservoirs. SPE $\mathrm{An}$ nual Technical Conference and Exhibition. https://doi.org/10. 2118/181392-ms.

Yuan, B., \& Wood, D. A. (2018). Overview of formation damage during improved and enhanced oil recovery. In Yuan, B., \& Wood, D. A. (Ed.). Formation damage during improved oil recovery (pp. 1-20). https://doi.org/10.1016/b978-0-12-8137826.00001-4. 